\title{
Relaciones infraestructurales: agua, poder político y el surgimiento de un nuevo régimen despótico*
}

\author{
Veronica Strang ${ }^{* *}$ \\ Institute of Advanced Study, Durham University, Inglaterra
}

DOI: https://doi.org/10.22380/2539472X.575

\begin{abstract}
RESUMEN
Ya han pasado sesenta años desde que Karl Wittfogel destacara una relación clave entre el poder político y la propiedad y el control del agua. Estudios posteriores han sugerido, en un sentido acorde, que la exclusión de la propiedad de recursos esenciales representa una forma profunda de exclusión —una pérdida de participación democrática en la dirección societaria- Varios campos de desarrollo teórico han clarificado estos temas. Algunos antropólogos han explorado la relación recursiva entre arreglos políticos y sistemas de creencia cosmológicos. Las definiciones estrechas de propiedad han sido cuestionadas al tomarse en consideración formas más diversas de propiedad y control de los recursos. Los análisis de la cultura material han mostrado cómo esta
\end{abstract}

amplía la agencia humana, además de tener capacidades de agencia en sí misma; y exploraciones sobre infraestructuras han destacado su papel en la constitución de relaciones sociotécnicas y políticas. Tales aproximaciones son fácilmente aplicables al agua y a la cultura material a través de la cual es controlada y usada. A partir de una investigación histórica y etnográfica sobre el agua en Australia y el Reino Unido, este artículo traza las relaciones cambiantes a lo largo del tiempo entre creencias cosmológicas, infraestructura y arreglos políticos, y sugiere que la actual tendencia hacia la privatización transnacional de la propiedad del agua abre la puerta al surgimiento de nuevos "regímenes despóticos".

Palabras clave: propiedad del agua, gobernanza del agua, relaciones humanas y no humanas, Reino Unido, Australia.

\footnotetext{
* $\quad$ "Infrastructural Relations: Water, Political Power and the Rise of a New 'Despotic Regime'” fue publicado originalmente en la edición 9 (2) de Water Alternatives, en el 2016. El ICANH agradece a la autora y a la revista original la autorización de su traducción y reimpresión para el dosier especial de la RCA sobre antropologías del agua.

** $\quad$ Profesora del Departamento de Antropología de la Universidad de Durham y directora ejecutiva del Instituto de Estudios Avanzados de la misma institución. Es una de las antropólogas más reconocidas en el estudio del agua desde las ciencias sociales y su trabajo ha sido fundamental para entender las relaciones entre cultura, agua y paisaje. Ha realizado investigaciones etnográficas en Australia, Reino Unido y Nueva Zelanda. Entre sus publicaciones se cuentan: Water: Nature and Culture (Reaktion Books/University of Chicago Press, 2015); Gardening the World: Agency, Identity, and the Ownership of Water (Berghahn, 2009); The Meaning of Water (Berg/ Bloomsbury, 2004) y Uncommon Ground: Cultural Landscapes and Environmental Values (Berg, 1997), y numerosos artículos. veronica.strang@durham.ac.uk.
} 


\section{Introducción}

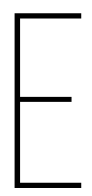

n 1957, cuando Karl Wittfogel propuso, a partir de un estudio sobre el agua y la gobernanza en Asia, que había una relación intrínseca entre el control del agua y el poder político, tuvo poca dificultad para persuadir al mundo académico de que esta era una suposición razonable. A lo largo de la historia y a través de las culturas, toda sociedad humana ha valorizado, y a menudo venerado, el agua como el elemento más esencial y como la fuente de salud y riqueza. De manera que la noción de una relación clave entre el control material del agua y el poder político era incontrovertible: ¿cómo puede no empoderar dirigir el más vital de los elementos? Y este potencial de control político a través de la propiedad del agua —algunas veces hegemónico - ha sido destacado en trabajos posteriores, como los de Worster (1992) y Reisner (1993).

Algo más polémico fue el argumento de Wittfogel referente a que el control centralizado del agua habilitó “regímenes despóticos”, y además sugirió que la creación de grandes infraestructuras de irrigación había requerido y posibilitado formas centralizadas de gobernanza y había hecho posible el surgimiento de Estados jerárquicos y despóticos. La idea de una relación recursiva entre estructuras físicas y políticas atrajo a aquellos interesados en cómo se materializa el poder. Por ejemplo, Marvin Harris (1979) situó la infraestructura como el principal mecanismo a través del cual las sociedades formulan relaciones con los ambientes. Luego, algunos análisis en los estudios de sistemas técnicos y sociales describieron la tecnología como "un fenómeno político" en el que "prestaciones" (affordances) específicas son promovidas por discursos simbólicos y rituales, y las infraestructuras contribuyen a la constitución de las relaciones sociales (Anand 2012; Foucault 1972; Pfaffenberger 1992, 282, 284). Pfaffenberger señaló cómo en Sri Lanka "prácticamente todo aspecto de la vida social, incluyendo la vida familiar y el culto, fue diseñado junto con las represas y los canales” $(1992,291)^{1}$.

Pero el análisis de Wittfogel también provocó serias críticas, tanto por parte de los sinólogos que promovían una visión más matizada de los arreglos políticos chinos (Needham 1954-2008), como de aquellos con teorías alternativas sobre la formación del Estado (Carneiro 1970; Hocart 1970). Aunque, en líneas generales, los académicos han estado de acuerdo en los últimos cincuenta años con que existe una importante relación entre el poder y el control del agua, un análisis más detallado de las formas en que el agua se entrecruza con las relaciones 
sociales y políticas ha develado un panorama más complejo que reconoce que muchos tipos de poder — no solo los regímenes despóticos - son habilitados a través del control y manejo de este recurso (Glick 1996; Lansing 1991).

Igualmente, con base en algunos análisis de la cultura material que exploran las capacidades de agencia de los artefactos (Boivin 2004; Gell 1998; Knappett y Malafouris 2008; Tilley 2007), otros dirigieron estas teorías hacia los recursos naturales y los arreglos infraestructurales a través de los cuales son controlados (Boivin 2008; Harvey y Knox 2010; Strang 2004, 2015). Es evidente que -ya sean artefactos o elementos - los significados de los objetos y su agencia potencial pueden transformarse con los cambios en el contexto social o político (Appadurai 1986). Tal como lo advierten Orlove y Caton (2010), el agua fluye a través de muchos ámbitos de la vida social y los conecta, razón por la cual hay múltiples formas de entenderla y valorarla (véase también Helmreich 2011). Estas multiplicidades producen una variedad de instituciones y procesos para manejar y distribuir los recursos hídricos, todo lo cual expresa no solo relaciones sociales sino también políticas.

Este artículo se enfoca en la relación entre agua y poder, y aborda en particular el papel de la infraestructura, enmarcándose en varios ejes temáticos: trabajos recientes sobre las muchas formas de propiedad que se pueden ejercer sobre el agua, conceptos de relaciones humanas-ambientales y teorías sobre la agencia y la materialidad. Señala que un elemento central - a menudo ignorado en los análisis del agua y el poder - son las creencias cosmológicas y los valores subyacentes (religiosos o laicos) que reflejan y afirman los arreglos societarios. Por ejemplo, llama la atención sobre una importante relación entre el desarrollo de infraestructuras del agua a gran escala y la euhemerización (humanización) de deidades religiosas (Strang 2014a).

La medida más clara de la igualdad social y política es la distribución de los derechos de propiedad (Widlok y Tadesse 2005). Hay múltiples maneras en que la propiedad y el control de recursos esenciales y sistemas materiales relacionados pueden ser distribuidos. Aun cuando estos son controlados por un gobierno centralizado, el Estado puede adoptar papeles muy diferentes. Puede actuar (como lo ha sugerido Wittfogel 1957) como un "otro" para la gente e imponer un régimen despótico; puede asumir un papel paternal como representante "de" la gente o puede actuar más directamente “como” la gente, respaldado por arreglos de propiedad colectivos (Alexander 2004). También hay una pregunta sobre si el control centralizado conduce inevitablemente a formas de empoderamiento que alienan a aquellos “a cargo”, y esta posibilidad está muy bien ilustrada por el análisis de Herzfeld sobre cómo las burocracias se tornan “indiferentes” hacia 
la población que están dirigidas a servir. El potencial para conducir a tal alienación - sin duda un criterio clave para el "despotismo" - lógicamente se incrementa cuando tal gobernanza se encuentra alejada de manera significativa de las redes sociales y políticas capaces de demandar rendición de cuentas.

Un proceso de creación de jerarquías y el surgimiento de élites gobernantes se hacen evidentes en las tendencias a largo plazo hacia el cercamiento y la privatización de la tierra, el agua y otros recursos, lo cual ha suscitado un cambio crucial en la propiedad y en las relaciones sociales (Hann 1998). Esta hegemonía a menudo ha subsumido arreglos más colectivos y arguyo que, al hacerlo, ha privado sistemáticamente de voz y voto a la mayoría de los seres humanos, así como a los no humanos, poniendo el control del agua y el poder en cada vez menos manos. También hay asuntos de género para destacar: el despojo ha tendido no solo a reemplazar la propiedad común del agua por la de las élites, sino que también ha favorecido el control masculino del agua y del poder (Coles y Wallace 2005; Lahiri-Dutt 2006).

En algunos países se ha vuelto común llevar compañías privadas para conformar asociaciones público-privadas (APP) con el fin de manejar el aspecto operacional del abastecimiento urbano de agua, así como la irrigación para la agricultura, mientras que la propiedad pública de infraestructura, que tiene altos costos de mantenimiento, a menudo ha sido retenida por el Estado. Por ejemplo, en Estados Unidos ha habido un incremento constante de las APP y al día de hoy "desde Nueva York hasta California más de 2.000 obras de infraestructura son manejadas por arreglos contractuales de asociación público-privada” (National Association of Water Companies 2012), y varios de estos contratos cuentan con la participación de grandes compañías transnacionales de agua, tales como Veolia, Suez Environment y RWE.

Internacionalmente, el Banco Mundial y el Fondo Monetario Internacional han promovido la privatización del agua como una manera de posibilitar a los países en desarrollo atender los asuntos relativos a su deuda nacional (dando lugar a variadas respuestas), y las compañías de agua en los países industrializados se han vuelto cada vez más atractivas para los inversionistas privados. Así, Wolff y Palaniappan (2004) señalan que "el número de personas atendidas por compañías privadas ha crecido de 51 millones en 1990 a cerca de 300 millones en el 2002. Solo 6 compañías de agua pasaron de tener presencia en 12 países en 1990 a estar en más de 56 países en 2002” (1). Existen variadas y diferentes fórmulas de propiedad del agua en estas privatizaciones parciales o totales, pero todas se enfocan principalmente en la adquisición de derechos para extraer, incautar, dirigir y distribuir el agua, otorgándose así el control material de esta. 
Dada la amplia tendencia internacional hacia la privatización, es útil considerar casos en los que ha habido un incremento notable en la adquisición de los derechos sobre el agua por parte de las corporaciones transnacionales. En el Reino Unido, la propiedad y el control del agua dulce fueron vendidos en 1989 a grandes corporaciones transnacionales, mediante la privatización directa de la industria que la suministra. Para los órganos legislativos nacionales, la Oficina de Servicios de Agua (Office of Water Services) y la Agencia del Medioambiente (Environmental Agency) ha sido difícil regular dichas corporaciones de forma efectiva (Bakker 2003, 2005; Strang 2004; 2018). En Australia, con la privatización de facto (a través de esquemas de comercialización del agua y la venta de licencias de extracción), grandes compañías de irrigación han sido compradas por importantes corporaciones transnacionales que ofrecen una protección regulatoria igualmente inefectiva de las necesidades locales, sociales y ecológicas (Strang 2013).

Con base en una investigación etnográfica de largo plazo realizada con usuarios de agua en cuencas hidrográficas ${ }^{2}$, este artículo presenta dos estudios de caso. El primero analiza la privatización de compañías de suministro de agua de consumo doméstico en Inglaterra; el segundo examina el cambio de propiedad de grandes compañías de irrigación en Australia. En ambos casos el artículo busca llenar brechas clave entre la literatura referente a la propiedad y aquella que trata el tema de la cultura material y la agencia, así como considerar cómo las relaciones sociales y políticas se materializan a través de los desarrollos infraestructurales. La hipótesis central es que la transferencia de la propiedad y el control del agua a manos privadas - ya sea jurídica o de facto-, combinada con mecanismos de regulación débiles, representa una disminución del poder del Estado y una transferencia concomitante de la dirección del control político a una red internacional de corporaciones transnacionales que responde principalmente a sus accionistas y a las fuerzas de mercado antes que a las poblaciones de estos países.

Con el ánimo de incentivar futuras investigaciones y debates sobre estos temas, el artículo plantea las siguientes preguntas: ¿qué pasa cuando el control del agua dulce se pone en manos de compañías situadas por fuera de las fronteras nacionales y societales?, ¿qué tipo de relaciones emergen entre las corporaciones transnacionales y las comunidades y ambientes regionales y locales?,

2 En Reino Unido, estas cuencas incluyen la del río Stour en Dorset y se enfocan en la autoridad reguladora de servicios de agua (Water Services Regulation Authority [OFWAT]), en la región del Támesis; en Australia, el río Mitchell en Cabo York y el río Brisbane en el sur de Queensland. 
¿cuál es el papel material y social de la infraestructura hídrica en estas relaciones? Y ¿existe un riesgo real de que, al transferir el control de la infraestructura de suministro del agua a entidades externas, se abra la puerta a comportamientos “despóticos"?

Las imágenes populares del despotismo tienden a retratarlo como malvado y absoluto, pero propiamente hablando, el despotismo simplemente se refiere a un régimen que no rinde cuentas, que no está regulado y que sobre todo es antidemocrático. De hecho, el despotismo puede ser malvado e insolidario, pero también puede ser un despotismo ilustrado y buscar el beneficio de la sociedad. Sin embargo, su poder es siempre ilimitado. Los gobiernos debilitados por la pérdida de la propiedad democrática de recursos vitales se encuentran en una situación de desventaja para regular a las compañías que manejan el agua privatizada, aun cuando permanezcan dentro de los límites nacionales. Su capacidad para controlar corporaciones poderosas es aún más débil cuando estas están ubicadas en el exterior. No es mi intención satanizar estas corporaciones - que son muy diversas-, sino solamente sugerir que la tendencia emergente hacia la propiedad transnacional les permite actuar, literalmente, sin ninguna restricción. Estas corporaciones pueden, y algunas veces lo hacen, optar por ser "iluminadas" en sus decisiones.

Pero creo que al colocar la propiedad de los recursos hídricos vitales en las élites transnacionales y no regular efectivamente sus actividades, también se corre el riesgo potencial de conducir a comportamientos “despóticos” que pueden ignorar los derechos e intereses sociales y ambientales locales con impunidad.

Como lo señaló uno de los evaluadores de este artículo, en los países en desarrollo el impacto de tal falta de restricción puede ser extremo (véase, por ejemplo, el trabajo de Mains [2012] sobre privatización e infraestructura en Etiopía). Pero aun en sociedades en gran medida protegidas por las economías del primer mundo, hay impactos sociales y ambientales. En el Reino Unido, el aumento de la pobreza de agua entre los más desfavorecidos ha llegado con los incrementos masivos en el precio a raíz de su privatización (Huby y Bradshaw 2012) tralia son aleccionadoras tanto la degradación generalizada de los ecosistemas

En el Reino Unido las tarifas del agua aumentaron en un $60 \%$ en los primeros cinco años que siguieron a la privatización de la industria en 1989. Veinte años más tarde, Huby y Bradshaw (2012) encontraron que el $23,6 \%$ de los hogares en Inglaterra y Gales experimentaban pobreza de agua en la medida en que las tarifas de suministro continuaban aumentando, superando considerablemente la inflación y el promedio de los ingresos. Los autores estiman que este número puede duplicarse para el 2033. 
frágiles, como las presiones sobre los usuarios del agua río abajo debido a la intensificación agrícola y la irrigación excesiva (Australian Bureau of Statistics [ABS] 2003a) ${ }^{4}$.

\section{Propiedades materiales}

El vínculo entre agua y poder es una expresión de las relaciones materiales. El ejercicio del poder no es posible si este no se puede expresar de forma material, en este caso, a través del control físico de los cuerpos de agua o de la capacidad para determinar (desde cualquier distancia) quiénes se beneficiarán del flujo del agua. Sin embargo, las relaciones materiales no se establecen solo entre personas. Todos los regímenes de control del agua se ven influenciados por las propiedades físicas del agua y sus comportamientos específicos. La fluidez del agua, la dificultad para capturarla y contenerla y la variabilidad en los flujos hidrológicos inevitablemente desafían las certezas de propiedad y control (Strang 2011). Todo régimen de agua, por más que sea técnicamente competente, debe enfrentar la realidad de que el agua tiene capacidades físicas agentivas que no siempre pueden ser dirigidas y en ciertos momentos pueden superar los esfuerzos humanos (Edgeworth 2011). Igualmente, los materiales que componen la infraestructura del agua tienen sus propiedades y comportamientos, los cuales definen las oportunidades y limitaciones para su diseño (Mukerji 2009). Por consiguiente, cada régimen de gestión es una negociación entre los arreglos sociopolíticos, las infraestructuras materiales que contienen y dirigen el agua y los caprichos de los procesos hidrológicos.

Esto subraya de manera útil un entendimiento, encapsulado por la teoría del actor-red (conocida como ANT por sus siglas en inglés), de que las relaciones humanas-ambientales involucran múltiples actores humanos y no humanos (Latour 2005). Tal como lo han dejado en claro la ANT y los trabajos relacionados con sistemas técnicos y sociales (STS), todos están comprometidos en procesos fluidos en los que interactúan dinámicamente (Harvey 2012). Estos trabajos son

4 En una encuesta realizada en el 2003, el ABS encontró que un 59\% de la tierra en Australia (456 millones de hectáreas) se usaba para la agricultura y era irrigada por el $70 \%$ de su agua dulce. Esto tuvo como consecuencia la extinción o disminución de muchas especies nativas, grandes cambios en el caudal del agua e impactos significativos en la calidad de la tierra y el agua. Un 10\% de los agricultores reportaron problemas con la salinidad (ABS 2003a) e informes posteriores (véase estudio de caso) han mostrado una intensificación agrícola cada vez más acentuada (especialmente en cuanto a la irrigación) y severos impactos acordes con estos cambios. 
complementados por la antropología de la infraestructura, que entiende este asunto de manera relacional y ecológica (Star 1999) ${ }^{5}$. La definición de Larkin es útil:

Las infraestructuras son redes construidas que facilitan el flujo de bienes, personas o ideas y permiten su intercambio a través del espacio. Como formas físicas moldean la naturaleza de una red, la velocidad y dirección de su movimiento, sus temporalidades y su vulnerabilidad para dañarse. Constituyen la arquitectura para la circulación, literalmente sostienen a las sociedades modernas y generan el entorno ambiental de la vida cotidiana. $(2013,328)$

Larkin (2013) también destaca el señalamiento de Hughes (1993) en cuanto a que las infraestructuras amalgaman técnicas financieras, administrativas y tecnológicas, y nos recuerda la útil observación de Foucault (2010) de que esto constituye "el aparato de la gubernamentalidad" $(70)^{6}$.

Así como los flujos de agua muestran fluctuaciones y cambios en el tiempo, las infraestructuras del agua experimentan cambios tecnológicos y desarrollos ${ }^{7}$, tal como sucede con los distintos grupos sociales y sus arreglos comprometidos con estos cambios a escala local, regional, nacional y ahora internacional. De manera que al tener en cuenta cualquier régimen de gobernanza y control del agua y sus expresiones infraestructurales, hay necesidad de reconocer que todos los participantes - incluyendo las personas, la cultura material, el agua y el ambiente más amplio, sus habitantes humanos y no humanos, las cosas materiales- están involucrados en procesos fluidos y algunas veces transformativos.

Sin embargo, tal como lo he argumentado en otras ocasiones (Strang 2011, 2014b), ni siquiera las relaciones sociales o materiales son absolutamente fluidas: todas tienen una dinámica histórica. Los flujos de agua están sujetos a las leyes físicas y a los ciclos estacionales que, aunque difíciles de predecir con exactitud, muestran patrones consistentes. A menudo los arreglos sociales, espaciales y políticos tienen un fuerte momento y continuidad en el tiempo. Estas continuidades se apoyan en su expresión material, que, como se anotó previamente, proporciona una afirmación recursiva de creencias, valores y prácticas específicas. Gandy (2011) señala que la infraestructura es también un producto de procesos simbólicos y de representación que articula “las interrelaciones

\footnotetext{
$5 \quad$ Para ampliar, véase Niewöhner (2015).

$6 \quad$ Para ampliar, véanse Scott (1998) y Mukerji (2010).

7 Esto puede implicar mejoras o deterioros, e históricamente estos últimos algunas veces se han visto involucrados en el colapso de regímenes políticos (Biswas 1970).
} 
entre dominios visibles e invisibles” (58). Esto incluye las relaciones de poder entre todos los participantes humanos y no humanos. Como lo dice Star (1999), estudiar "cosas aburridas" puede ser iluminador: "Si usted estudia una ciudad y desatiende sus alcantarillados y fuentes de energía (como lo han hecho muchos), va a perder aspectos esenciales de la justicia distributiva y del poder” (379).

La deconstrucción de las relaciones infraestructurales se complementa con el trabajo de los especialistas en cultura material. La representación que hace Gell (1998) de la cultura material como una extensión “prostética” de la agencia humana es fácilmente aplicable a las infraestructuras del agua para iluminar cómo estas forman y están formadas por las ideas dominantes (así como por las propiedades mismas del agua). Como señala Gell (y esto también es retomado por Harvey y Knox [2012] en relación con la infraestructura), la tecnología tiene sus propias capacidades para "encantar" (Gell 1992).

Aun cuando ha habido cambios y desarrollos periódicos en la infraestructura hídrica a través de la historia, las grandes inversiones en trabajo y materiales significan que muchos de los sistemas construidos - tales como los sistemas victorianos de alcantarillado en Londres o los tanques de agua en India- han mostrado una longevidad considerable, de manera que llevan consigo las materializaciones de ideas anteriores a nuevos arreglos sociales y políticos. Pero ya sea que perpetúen o no creencias y valores previos, el control del agua forma parte integral de las capacidades de las personas para ejercer agencia y para construir identidades particulares. Por ejemplo, los conflictos entre agricultores, grupos conservacionistas, usuarios del agua para actividades recreativas y comunidades indígenas emergen de las diferentes maneras de luchar por representar ciertas identidades y valores grupales e individuales.

En la escala societal hay un continuo de posibilidades en el ejercicio de la agencia humana, fluctuando desde los métodos moderados de gestión de las sociedades cazadoras-recolectoras, que dejan un papel directivo considerable a las especies no humanas y a las cosas, pasando por formas sutiles pero más contundentes de control ambiental, hasta imposiciones más extremas de tecnologías con mayores capacidades de anular los procesos no humanos del ecosistema (Strang 2005, 2009). En la medida en que esto implica desarrollos cada vez más sofisticados en la infraestructura del agua, se han facilitado "prostéticamente" nuevas distribuciones de poder y agencia, relaciones humanas-ambientales y tipos de "propietización”.

Sin embargo, el control infraestructural puede ser esquivo. Por ejemplo, Wittfogel sugirió que los canales chinos que permitieron el "despotismo oriental” formaron una parte central de las actividades sociales, económicas y 
religiosas de esta región hasta cerca de 1850, cuando su sedimentación y deterioro alcanzaron un punto donde el Gobierno no pudo seguir abordando los problemas de irrigación del país (Halsema y Vincent 2006). La dinastía colapsó en 1911. La sedimentación, el deterioro y la falta de mantenimiento en periodos de inestabilidad política contribuyeron igualmente a la desaparición de las sociedades que dependieron de la irrigación en Mesopotamia y América Central, grandes dinastías en el valle del Indo y otras semejantes distribuidas a lo largo de Asia (Kahlown et al. 2006).

No obstante, cada caso proporcionó una clara muestra de la capacidad de las grandes infraestructuras del agua para sostener el poder político, así como formas de gobernanza a gran escala. Siguiendo a Durkheim (1961), he argüido que hay una conexión entre la capacidad creciente del control material instrumental y los movimientos tendientes a la euhemerización en los sistemas de creencias religiosas (2014a). Existen abundantes ejemplos históricos: la creación de grandes tecnologías de irrigación les facilitó a los faraones de Mesopotamia lograr un estatus divino (Biswas 1970). Los canales de riego les concedieron a los reyes-dioses aztecas similares responsabilidades para hacer llover (Ferguson 2000). En China, Yu el Grande alcanzó un estatus mitológico como el maestro hidrólogo (aunque no desplazó exactamente a los dragones como manifestaciones del poder del agua) (Pietz 2006); y en el Levante mediterráneo, y eventualmente a lo largo de Europa, dioses individuales patriarcales reemplazaron deidades paganas animistas como proveedores del agua benéficos (o punitivos) (Harrison 1999).

En cada caso, se trata de movimientos desde "religiones de naturaleza", que valoraban deidades no humanas, hacia panteones de dioses humanizados y monoteísmos patriarcales, que se entrecruzaron con aumentos en las capacidades tecnológicas para dirigir eventos en el ambiente material. Existía una bifurcación concomitante en los conceptos de naturaleza y cultura (Plumwood 1993). Aquí no deseo insinuar algún tipo de progresión evolutiva, simplemente quiero sugerir que es útil considerar las interrelaciones entre trayectorias tecnológicas y religiosas y los patrones más amplios que estas conforman, en particular cuando llevan a nuevas formas (y en general más directivas) de involucramiento ambiental. 


\section{Relaciones modernas tempranas con el agua}

En el periodo moderno temprano, la industrialización situó a algunas sociedades en una rápida vía tecnológica. Con nuevas capacidades científicas y de ingeniería, la infraestructura del agua europea floreció con rapidez (Tvedt y Oestigaard 2010). Los canales, la energía hidráulica y el desarrollo de grandes sistemas de almacenamiento y suministro de agua facilitaron la rápida expansión urbana y el acelerado crecimiento industrial. De allí surgió, primero en los países europeos y sus colonias, y después en otras partes del mundo, un programa masivo de construcción de represas para suministrar riego y, más tarde, generar electricidad. Así como se afirmaba y expandía la condición de estatalidad, esto creó formas más diversas de propiedad y manejo del agua, por parte de naciones, Estados, municipios y propietarios de tierras. Tal como los grandes avances tecnológicos lo habían hecho previamente, aumentaron también las desigualdades sociales, empoderando a aquellos capaces de establecer un papel directivo en el control del agua.

Si bien el monoteísmo patriarcal y las nociones de dominio continuaron proporcionando un telón de fondo a las estructuras sociopolíticas coincidentes, la autoridad intelectual giró cada vez más hacia la ciencia, fortaleciendo una visión del mundo material a la vez como objeto y sujeto de la preeminencia humana. Esto se reflejó en los sistemas de infraestructura - canales y desviaciones, bombas y embalses - cada vez más capaces de imponer la agencia humana, hasta el punto que los procesos ecológicos normales podían ser profundamente anulados.

De manera que en los siglos que condujeron al presente, los derechos e intereses entre los seres humanos y no humanos fueron considerablemente reconfigurados y redistribuidos. La priorización de los intereses humanos y la promoción de formas neoliberales ${ }^{8}$ de propiedad y gobernanza del agua abrieron el camino hacia una lógica de instrumentalismo en la que el agua y otros recursos, así como las especies no humanas, podían ser vistos como existiendo principalmente para proveer "servicios ecosistémicos" a la humanidad o, más específicamente, a algunos grupos humanos. Tal como lo señalan Orlove y Caton (2010), esto ha producido conceptos tales como el manejo integrado de los recursos hídricos, que predomina hegemónicamente en los debates globales sobre el agua. Así,

8 Aquí el neoliberalismo se define como una ideología que valora la competencia en un libre mercado y la propiedad privada de los recursos, y que además construye la condición de persona en términos individuales. 
mientras que el instrumentalismo en sí mismo no es nada nuevo en las relaciones humanas-ambientales, yo sugiero que el dominio creciente de este tipo de gestión es indicativo de importantes cambios en creencias y valores, así como de un giro clave en la relación de poder entre los seres humanos y no humanos.

El control del agua y la infraestructura ha sido central para la conformación de los Estados nación modernos. Por ejemplo, Swyngedouw (2015) describe la formación hidráulica del Estado español en donde los conflictos sobre la propiedad y el control del agua estaban dominados por un compromiso centralizado de intervenir con ingeniería el ambiente, hasta el punto que los intereses de las comunidades y ambientes locales eran subsumidos por las prioridades económicas y políticas (véase también Garrido 2014). Hay un patrón que ha aparecido en diversas formas y en muchas áreas, a través del cual los derechos sobre el agua son centralizados y comercializados (véase Harris et al. 2013; Sultana y Loftus 2012). Tal como lo señalan Norman et al. (2015), hay asuntos críticos de escala en la transferencia de los derechos sobre el agua de instituciones locales hacia otras más grandes. Y por supuesto que esto nos lleva a la cuestión de la propiedad global y transnacional del agua.

\section{Formas fluidas de gobernanza}

\section{Agua pública y privada en Inglaterra y Gales}

Los conflictos sobre el agua en el Reino Unido durante los siglos XIX y XX resaltan tensiones como las que muchos Estados nación han experimentado al tratar de reconciliar diferentes visiones sobre quién debe tener la propiedad y el control del agua, mientras que también tratan de manejar grandes diferencias en escalas políticas, sociales y materiales. Hasta el siglo XIX, los propietarios de tierras agrícolas mantuvieron derechos ribereños, aunque para esta etapa la mayoría de la tierra estaba en manos de un segmento muy pequeño de la sociedad. Inicialmente, las industrias lograron el acceso al agua al concentrar sus instalaciones a lo largo de los ríos y extraerla directamente de estos. Sin embargo, la mecanización de la agricultura y las nuevas formas de producción llevaron a la mayoría de la población y a las industrias —en rápida expansión-a las ciudades, lo cual creó una necesidad apremiante de suministro del agua por tubería para uso doméstico e industrial. 
Esto condujo a una rivalidad por la propiedad ${ }^{9}$. Los industrialistas victorianos invirtieron en compañías privadas de suministro de agua y algunas veces en embalses, en parte para apoyar sus actividades económicas y en parte para lograr estatus y distinción social, haciendo eco del papel de las antiguas abadías cristianas como suministradoras filantrópicas de agua (Gorsky 1999; Himmelfarb 1995; Prochaska 2008). Esto les permitió asumir una responsabilidad paternal por (y de) un bien común vital que - en una sociedad cristiana - todavía era simbólicamente representativo del espíritu. Por otro lado, estaban los municipios: ayuntamientos locales (también compuestos por prósperos terratenientes e industriales) que vieron el suministro de agua como una responsabilidad política y social, de naturaleza pública. En ambos casos, aunque el agua en sí misma todavía era considerada un bien común, el control de las fuentes de agua y de la infraestructura de su suministro confería el derecho de propiedad de facto, y por consiguiente la cuestión de si esta propiedad debía ser pública o privada tenía un peso político considerable. Los primeros años del siglo XX trajeron una intensa argumentación sobre esta cuestión, al mismo tiempo que la propiedad de la infraestructura de suministro del agua pasaba de un lado al otro entre las compañías privadas y los municipios (Bakker 2003; Strang 2004).

Los debates sobre el "bien común” que proveía el agua se superpusieron a aquellos interesados en los derechos democráticos. La Primera Guerra Mundial creó importantes presiones para una concesión más amplia de derechos democráticos. A medida que el sufragio había sido por largo tiempo dependiente de la propiedad de bienes, estaba vinculado con debates sobre la propiedad de recursos claves. Antes de la guerra, solo un $58 \%$ de la población masculina tenía derecho a votar. La Ley de Representación del Pueblo de 1918, aunque todavía excluía a las mujeres menores de 30 años, concedió el sufragio para todos los hombres británicos mayores de 21 años, junto con cerca del $40 \%$ de las mujeres (Representation of the People Act, British Government 1918). El activismo subsiguiente logró el derecho al voto para todas las mujeres mayores de 21 años con la aprobación de la Ley de Representación del Pueblo-Sufragio Igualitario de 1928 (Representation of the People-Equal Franchise Act., British Government 1928).

La Segunda Guerra Mundial impulsó aún más una identidad nacional y una gobernanza estatal comunes, profundizando así el apoyo popular a la inclusión democrática, así como la propiedad y el control público de los recursos. Después de la guerra, un gobierno laborista proporcionó suficiente ímpetu para la

9 La raíz etimológica de rival es río. Esta rivalidad es bastante literal, está basada en la idea de que quienes vivían a las orillas de un río (rivus en latín) se volvían competidores por el acceso al agua. (N. de la T.). 
nacionalización de las compañías de suministro de agua así como de otros servicios públicos esenciales. El Gobierno también esperaba impulsar el crecimiento económico apoyando los desarrollos de la infraestructura. Por consiguiente, el suministro de agua se convirtió (principalmente) en la responsabilidad de las autoridades regionales del agua bajo un gobierno y una legislación nacional cada vez más centralizados. Aunque las autoridades locales no rendían cuentas en la misma medida que las autoridades municipales anteriores, disfrutaban de una relación bastante positiva con la población a la que le suministraban el agua. Como lo recordó nostálgicamente un empleado de la compañía de agua Wessex, "se han ido los días hermosos cuando yo empecé a trabajar. En aquellos días, en los 1960, el público, el pueblo del país, todos estaban con nosotros en ese entonces" (Strang, notas de campo 1999).

Sin embargo, tal democratización también significaba que los gobiernos centrales y regionales asumían la responsabilidad de las tarifas del suministro de agua. No sorprende que hubiera reticencia a subir los costos de un "bien común” esencial, por la recriminación política que esto conllevaba. Aunque los flujos y la calidad del agua eran vistos ahora dentro del ámbito de la ciencia y de la ingeniería, este lenguaje biofísico solo afirmaba, en vez de socavar, el estatus de larga data del agua como base del bienestar y de la salud económica, espiritual y física. Tal vez haciendo eco de los problemas de los gobiernos anteriores que asumieron la responsabilidad del agua, resultó difícil recaudar fondos para el mantenimiento y el desarrollo de la infraestructura. En 1989, esto permitió al gobierno de Thatcher argüir que solo privatizando la industria del agua se podría suministrar suficiente acceso a capital para invertir en nueva infraestructura y establecer un sistema más “eficiente” de suministro (Bakker 2003, 2005). Ligado a esto vino una reconstrucción conceptual del agua como una mercancía comerciable, lo que coincidió con la reformulación de los usuarios del agua como “consumidores”, y más recientemente como “clientes”, sugiriendo así que el agua es ahora el producto "cultural” de las compañías de agua que la tratan y la suministran, en vez de un bien común o parte de la Naturaleza ${ }^{10}$.

Haciendo caso omiso de las furiosas protestas públicas, la privatización del agua fue aprobada y también fueron vendidos otros servicios públicos, en teoría con acciones disponibles para todos, pero en la práctica capturadas en gran medida por los inversionistas corporativos (bancos, fondos de pensiones, compañías de inversión, etc.). Desde 1989, más de la mitad de las veintiuna compañías que

10 Aunque un concepto dualista de cultura y naturaleza sigue dominando la mayoría de los discursos sobre este tema, otros y yo hemos argüido que esta es una teorización problemática de las relaciones humanas-no humanas (Plumwood 1993, 2002; Strang 2005, 2015). 
surgieron de las diez autoridades del agua han sido compradas por corporaciones transnacionales y solo tres de las otras grandes compañías todavía cotizan en la bolsa y tienen sus sedes en el Reino Unido ${ }^{11}$.

Así, mientras la gobernanza y el manejo del agua se encuentran enredados en una compleja red de actores públicos y privados, el control de recursos e infraestructura clave está otra vez en manos de una pequeña élite, ahora más internacional, que difiere de manera crucial de aquella anterior compuesta por industrialistas victorianos y aristócratas terratenientes: por primera vez el poder y la agencia relacionados con el agua no residen en personas en la cima de una sociedad específica dentro de un ambiente material compartido, sino en una red transnacional de corporaciones internacionales cuyos roles directivos (y sus participaciones) pertenecen a menudo a no residentes. Los gobiernos nacionales y otros participantes en la gobernanza del agua (tal como la Unión Europea) tienen una capacidad limitada para regular el comportamiento de estas corporaciones en el manejo del recurso más esencial de todos, y aún menos para requerir que asuman responsabilidades sociales o ambientales más amplias. La autoridad reguladora de los servicios de agua en el Reino Unido (Water Services Regulation Authority [OFWAT]) controla las tarifas del agua, mientras que la Agencia del Ambiente tiene la responsabilidad de producir la legislación concerniente a la protección ambiental. En qué medida estas agencias pueden ejercer presión sobre las compañías de agua varía según el clima político, pero, debido a una persistente insuficiencia de recursos y a una falta generalizada de voluntad política

11 La propiedad extranjera de las compañías de agua del Reino Unido (en el momento de escribir) es como sigue a continuación:

Thames Water: consorcio de inversión dirigido por el grupo bancario y financiero Macquarie de Australia, con grandes inversiones de compañías de Abu Dhabi y China.

Severn-Trent: grupo de inversión canadiense Borealis, la Oficina de Inversiones de Kuwait y el Universities Superannuation Scheme (Plan de Pensiones Universitarias) del Reino Unido. Northumbrian Water: Cheung Kong Infrastructure Holdings (Hong Kong).

Essex y Suffolk Water: Cheung Kong Infrastructure Holdings (Hong Kong). Cambridge Water: Cheung Kong Infrastructure Holdings (Hong Kong).

Yorkshire Water: Citigroup, HSBC y el fondo soberano GIC de Singapur.

Affinity Water (anteriormente Veolia Water Central, Veolia Water East, Veolia Water Southeast): Morgan Stanley con sede en Estados Unidos e Infracapital con sede en Reino Unido.

Anglian Water: Osprey Acquisitions Limited, un consorcio de varias compañías con sede en el Reino Unido, Estados Unidos y Canadá.

Bristol Water: Capstone Infrastructure, con sede en Canadá, Grupo Agbar con sede en España y la Corporación Itochu con sede en Japón.

Sembcorp Bournemouth Water (anteriormente Bournemouth and West Hampshire Water): Sembcorp, con sede en Singapur.

South-East Water: CDPQ, con sede en Canadá, y Utilities Trust of Australia.

South Staffordshire: Alinda Infrastructure Fund con sede en Estados Unidos.

Wessex Water: corporación de Malasia YTL.

www.lovemoney.com/guides/21023/do-you-know-who-really-supplies-your-water. 
para desafiar a las grandes corporaciones, raramente son asertivas ${ }^{12}$. Como se mencionó en la introducción, esto ha resultado en considerables incrementos en las tarifas y en crecientes niveles de pobreza de agua (Huby y Bradshaw 2012).

En Reino Unido, a pesar tanto de las sequías como de las inundaciones, las compañías de agua privatizada se han mostrado reticentes a hacer inversiones en grandes depósitos de agua, que - si su único propósito es el de proveer suministros suplementarios o disminuir el riesgo de inundaciones- son necesarios solo de manera intermitente. Aunque han respondido a algunas directivas de la Unión Europea con nuevas plantas de tratamiento ${ }^{13}$ y renovaciones de la tubería para reducir los escapes de agua, se ha hecho muy poco esfuerzo para alejarse de las extracciones río arriba que, aunque baratas, son costosas ecológicamente y sus soluciones siguen enfocadas en la última etapa del proceso (end of pipe solutions). La calidad del agua fluvial ha mejorado, en gran medida por la desaparición de las industrias más contaminantes, pero sigue siendo difícil mantener flujos ecológicos normales. Algunos esfuerzos legislativos para abordar tales asuntos se llevaron a cabo con la Ley del Agua (Water Act) del 2003, que aumentó las responsabilidades del Gobierno para asegurar el uso sostenible de agua (Parliament of the United Kingdom 2003) ${ }^{14}$. Varios organismos independientes, tales como Waterwise, fueron establecidos para incentivar la conservación del agua, así como prácticas industriales ecológicamente más responsables. A la Agencia del Ambiente se le otorgaron mayores poderes para exigir prácticas industriales sostenibles. En el 2014, con más ímpetu por parte de los reguladores (OFWAT y EA 2011), se introdujo nueva legislación con el objetivo de desincentivar la extracción río arriba (Defra 2014). Las inundaciones recientes también han incrementado la presión política para establecer mayor control sobre los flujos de agua.

Sin embargo, las compañías de agua continúan resistiendo las compras y ventas de grandes volúmenes de agua, así como la reforma de las licencias de extracción (Walker 2014, 398). Además, al pretender trasladar las presiones mediante reformas al mercado, muchos de estos mecanismos legislativos fueron desmontados o marginados por el gobierno de coalición (Castree 2010). Es improbable que sean reintroducidos después de la victoria arrolladora de los conservadores en las elecciones del 2015, que en términos generales ha incrementado

12 En el transcurso de esta investigación también fui miembro por dos años de un comité regional de OFWAT (región del Támesis). objetivo inducir cambios de comportamiento en el consumo del agua. 
la presión sobre la OFWAT para que "se involucre más constructivamente y [...] reduzca la carga sobre las compañías de la regulación [de agua]” (Gray 2011, 5).

Aun con el desarrollo de electrodomésticos e instalaciones de plomería más eficientes y con incrementos sustanciales en las tarifas, desde el momento de la privatización los patrones de uso del agua en el hogar han demostrado ser muy estables. Con un ojo puesto en los ingresos y las ganancias, las compañías de agua han tendido a evadir el manejo de la demanda, a pesar de que hoy tienen acceso a tecnologías sofisticadas para tratar y transportar el agua y para medir y monitorear los flujos. Los medidores del uso se han expandido para penetrar en más del $30 \%$ de los hogares (Walker 2014). Los proveedores de agua ya pueden leer los contadores de agua domésticos y comerciales desde computadores centralizados y, aunque no se permite parar la provisión por completo ${ }^{15}$, pueden castigar el no pago de los recibos reduciendo los suministros a un goteo frustrante. Todas aquellas tecnologías materiales y fiscales reafirman la mercantilización del agua (Kopytoff 1986).

La medición también permite que las compañías de agua localicen los escapes y los ataques vandálicos. Como ejemplo de una forma clásica de protesta, está la "negativa” (Ortner 1995) que se presenta comúnmente cuando la escasez requiere la instalación de grifos públicos y las personas deliberadamente los abren para dejar correr el agua. Tales expresiones individuales de resentimiento contrastan fuertemente con respuestas anteriores a la escasez de agua, como la campaña Consérvela de los setenta, cuando las compañías públicas de agua convencieron fácilmente a más del $90 \%$ de los hogares y los negocios de reducir su uso del agua por lo menos en un $30 \%$ y en algunos casos, en un $40 \%$. Para el momento de la sequía de 1995, "el clima social había cambiado. El público culpaba a las compañías de agua y las compañías culpaban al público” (Ward 1997, 95). En el 2012, otra sequía produjo iguales intercambios injuriosos. Ni las compañías de agua ni sus “clientes” parecían dispuestos a colaborar para manejar el agua de manera sostenible. Walker (2014) describe esto como un fracaso de la "metagobernanza” causado por la naturaleza del intercambio capitalista y su producción de la naturaleza resultante:

Ahora los acuerdos multilaterales promueven la designación de un valor económico para el agua y endosan su concesión y consumo económicamente eficiente a la luz de otros usos económicos competidores (European Parliament 2000). El estatus económico del agua es cada vez

15 A las compañías de agua se les permitió cortar el suministro a los hogares o a los negocios que dejaran de pagar las facturas, hasta que el Gobierno laborista elegido en 1997 prohibió que lo hicieran. 
más transformado de un bien público a uno privado, su escasez es formulada como naturalizada y absoluta, y su manejo se determina en términos de la eficiencia económica. (390)

Los grupos ambientales han registrado la destrucción continua de los humedales en el Reino Unido, tomando nota de la calidad del agua comprometida, la pérdida de hábitat y la consiguiente pérdida o puesta en riesgo de múltiples especies (BAG 1996; English Nature 1996; RSNC 1992; RSPB 2011). Martin Spray, del Wildfowl \& Wetlands Trust (WWT), señala una mayor variedad de presiones:

La crisis financiera ha traído cortes y austeridad y ahora la amenaza de eliminar la legislación que se interponga en el camino del desarrollo económico. El medio ambiente ha sido marginalizado, visto como un lujo del que solo nos preocupamos en tiempos de prosperidad. No obstante, el ambiente natural, particularmente los humedales, soportan nuestra prosperidad y bienestar. (Citado en RSPB 2011)

Los asuntos descritos anteriormente sugieren que la renuncia a la gobernanza del agua para dejarla en manos del mercado, en particular de corporaciones transnacionales extranjeras, es problemática. Tales arreglos no parecen adecuados para producir prácticas sostenibles de uso del agua o una infraestructura que proteja los intereses humanos y no humanos a largo plazo. Tampoco han proporcionado un acceso fiable al agua o a ecosistemas funcionales en los que las necesidades de todas las especies sean satisfechas.

\section{La extracción de agua en Australia}

En Australia han ocurrido procesos similares de mercantilización del agua e impactos sociales y ambientales. Por supuesto que el contexto es bastante diferente: Australia tiene una densidad de población mucho más baja, un ambiente mucho más árido y una economía enfocada en la producción primaria. Sin embargo, existen algunas cosas en común con el Reino Unido en cuanto a la hoja de ruta hacia la privatización y la propiedad internacional del agua. La dependencia de Australia de la agricultura es también útil para resaltar las conexiones entre la producción local y las fuerzas de mercado globales.

En los dos siglos que siguieron a la colonización europea, la infraestructura de agua en Australia y su gobernanza se han alejado mucho de las formas moderadas de manejo y control igualitario del agua que mantenían los pueblos aborígenes (Builth 2002; Gammage 2011; Lourandos 1987; Tibby et al. 2006). Uno de los primeros actos de los colonizadores europeos fue apropiarse de las fuentes 
de agua más importantes. Rehusándose a reconocer la propiedad indígena de la tierra o de los recursos, pastores, ganaderos, agricultores y mineros establecieron la propiedad territorial de la tierra que, en ese periodo, incluía derechos ribereños para extraer el agua gratuitamente, ya fuera de los ríos o mediante perforaciones para acceder a las aguas artesianas subterráneas.

Los registros coloniales revelan una visión del mundo caracterizada por una mirada dualista e inmutable de la naturaleza y la cultura. Aunque el agua retuvo significados generativos centrales, estos fueron canalizados hacia una visión de la capacidad reproductiva interesada principalmente en el crecimiento material y económico. Al ver este ambiente desconocido como una naturaleza "hostil” y "salvaje”, y decididos a establecer una nueva nación, los colonizadores se embarcaron en un programa agresivo para ejercer su dominio y la deforestación fue recompensada con la propiedad de la tierra. Las cercas impusieron la autoridad territorial y las “fincas" se constituyeron en un baluarte contra la tierra salvaje (Schaffer 1988). Se desarrollaron apegos afectivos al lugar, pero la tierra y los recursos fueron vistos como mercancías alienables y el paisaje sensible de los aborígenes australianos fue revestido con un paisaje cultural enfocado en las oportunidades materiales (Strang 1997). El agua se encontraba allí para ser dirigida hacia las actividades económicas de los colonizadores, y sus habitantes no humanos fueron vistos como peligrosos o destructivos, como objeto de caza o como competencia prescindible sobre los recursos forrajeros.

La introducción de un modelo económico formado en climas templados tuvo efectos ecológicos significativos. El ganado de pezuñas duras castigó las delicadas estructuras del suelo, degradando los ecosistemas marinos y de agua dulce. La minería fue (y sigue siendo) ${ }^{16}$ perjudicial para la calidad del agua. La agricultura se intensificó rápidamente alrededor de los grandes ríos y la Gran Cuenca Artesiana (Great Artesian Basin) fue perforada miles de veces. Sin embargo, hacia finales de 1800 y principios de 1900, los flujos variables de agua del ambiente árido seguían siendo desafiantes, y, esperando lograr la seguridad del agua y cumplir con un deseo celoso (y de hecho semirreligioso) de “enverdecer el desierto”, Australia se embarcó en la construcción de esquemas de irrigación masivos, por ejemplo, en el área del río Snowy y en Queensland (Hill [1937] 1965). Bajo un sistema federal, constitucionalmente el agua era considerada propiedad de los Estados subsidiarios que competían por construir los

16 Muchas minas antiguas continúan lixiviando químicos venenosos al ambiente, y aunque ahora las compañías mineras reclaman haber prevenido que estos problemas sigan presentándose, la minería aluvial y la presencia extendida de canteras también siguen contaminando los ríos. 
esquemas más grandes de riego, principalmente destinados a servir los intereses de una clase terrateniente, la "squattocracy"17, que controlaba en gran medida los gobiernos estatal y federal. Los Estados asignaban el agua a los agricultores con base en su propiedad de la tierra y durante gran parte del siglo XX permitieron su extracción ilimitada.

Este statu quo permaneció hasta los años ochenta, momento en que el uso excesivo de agua (mayormente por los agricultores, pero también cada vez más por otras industrias) estaba creando problemas significativos con los flujos de agua. La producción de cultivos de irrigación se había expandido (constituyendo alrededor del 70\% del uso del agua dulce en Australia) y en los ochenta hubo un traslado hacia cultivos más rentables pero también más sedientos. El cultivo del algodón se triplicó entre 1985 y 1998, y para el 2000 estaba consumiendo el 12\% del agua usada en Australia. El arroz utilizaba casi el mismo porcentaje del agua (11\% del total) y el azúcar usaba el 8\%. El área irrigada pasó de 1.624.186 ha en 1985 a 2.056.580 ha en 1996-1997, es decir, tuvo un incremento del 27\%. En la misma década, el agua usada para riego aumentó en 7.700 gigalitros por año, es decir, en un $75 \%$ (ABS 2005).

Los flujos de agua no eran el único problema: en los noventa la irrigación también había empezado a salinizar y, en consecuencia, a inutilizar vastas extensiones de tierra (ABS 2015a) ${ }^{18}$. Se presentaban crecientes conflictos entre los usuarios del agua río arriba y los del río abajo, y el crecimiento poblacional y la expansión urbana habían dado lugar a una fuerte competencia por la demanda. Los votantes urbanos no solo querían suministros confiables para el uso doméstico sino acceso pleno al agua para recreación y, por lo tanto, apoyaban a los grupos conservacionistas en cuanto a las preocupaciones que planteaban sobre el bienestar ambiental. Por primera vez se requirió a los agricultores presentar planes de manejo de concesión del agua (Water Allocation Management Plans [WAMPS]), y con la Ley del Agua del 2000, los Estados empezaron a imponer límites volumétricos en las asignaciones y tomaron acciones para instalar medidores en las perforadoras y bombas de extracción (COAG 2004, 1). Sin embargo, el uso del agua para riego continuó expandiéndose: solo entre el 2012 y el 2013 hubo un incremento del $32 \%$ en el uso de agua en las granjas, de la cual el $93 \%$ se destinó

17 De acuerdo con la historiografía australiana, estos terratenientes adquirieron sus propiedades a través de la usucapión. [N. de la T.].

18 La salinización ocurre cuando la irrigación de cultivos de raíces poco profundas hace subir sales a la superficie, dejando los suelos inútiles para soportar cualquier vegetación (aun la nativa). Alrededor de 2 millones de hectáreas en Australia fueron categorizadas como salinas en el 2002 y se piensa que esta área puede incrementarse a 17 millones de hectáreas para el 2050 (ABS 2015a). 
a irrigación; un $43 \%$ procedía de esquemas de irrigación y un 25\% fue tomada directamente de los ríos, lagos y riachuelos (ABS 2014a).

Junto con esta expansión, estaba creciendo la presión por el reconocimiento de los derechos indígenas a la tierra y al agua. El movimiento por los derechos civiles había llevado en 1967 a un referendo constitucional para darles voz y voto a los aborígenes australianos y a los isleños del estrecho de Torres, seguido por un movimiento por los derechos a la tierra que trató de conciliar el derecho aborigen con el de los colonos australianos (Attwood y Markus 1999; Reynolds 1987). Estos esfuerzos culminaron en la Ley de Titulación al Nativo (Native Title Act) de 1993, que después de 200 años de negación, reconoció que los indígenas australianos tenían una forma anterior de propiedad de la tierra y de los recursos (Toussaint 2004). Sin embargo, al promulgar esta ley, se derribó el gobierno inusualmente liberal de Paul Keating, y el siguiente régimen de derecha reafirmó la propiedad y control del agua no aborígenes. Aun así, los reclamos de los indígenas continúan avanzando lentamente en los juzgados y algunos han sido exitosos, incluido un importante reclamo de derechos sobre el agua marina en la Tierra de Arnhem (Morphy y Morphy 2006) ${ }^{19}$. Respaldados por la Ley de Titulación al Nativo, los grupos aborígenes también han recuperado algunos derechos al uso tradicional del agua mediante los Acuerdos sobre la Utilización de las Tierras Indígenas.

Los esfuerzos de los pueblos aborígenes para recuperar sus derechos sobre el agua han sido impulsados en parte por la preocupación de restablecer sus propios valores y formas de manejo ambiental. En Australia, como en otras partes del mundo, las comunidades indígenas han criticado fuertemente los usos y prácticas de uso del agua y la tierra por parte de las sociedades coloniales, que a menudo entran en conflicto no solo con los valores de los indígenas sobre cómo "cuidar la tierra”, sino también con las creencias tradicionales sobre el mantenimiento adecuado de los flujos en el mundo material y espiritual (Barber et al. 2015). Una de las preocupaciones más comunes expresadas por los aborígenes australianos en relación con las infraestructuras del agua -y de las represas en particular- es que estas interrumpen los flujos “adecuados” del agua. Esto no es simplemente un asunto de alterar los flujos estacionales y de privar a los ecosistemas acuáticos del agua suficiente para soportar las especies no humanas: también se ve como un impacto más profundo sobre las tierras ancestrales y los espacios acuáticos, los dos concebidos como seres sintientes (Krause y Strang 2013). 
A pesar de algunas restituciones de derechos relacionados con las áreas marinas, la restauración del control indígena sobre el agua dulce ha demostrado ser difícil de lograrse (Altman 2004). Esto no es evidente inmediatamente porque los gobiernos federal y estatal han establecido formas “democráticas” de manejo del agua a través de grupos locales y regionales de gestión de cuencas, y estos incluyen a pueblos indígenas, así como a representantes de organizaciones de conservación. Sin embargo, la mayoría de estos grupos han sido capturados políticamente de manera efectiva por los intereses de la agricultura comercial y la industria que, con base en su importancia económica, han resistido a presiones subalternas para hacer grandes cambios al statu quo (Lawrence 2005; Strang 2009). Esto destaca una separación crítica (y común) en la gobernanza del agua, por cuanto los intentos para lograr sostenibilidad ambiental se han delegado a grupos no elegidos, en lo que podría describirse como una abdicación de la responsabilidad gubernamental, mientras que la propiedad y la gobernanza del agua para el uso doméstico y productivo han permanecido en las manos de agencias estatales y federales y, cada vez más, en las de corporaciones privadas.

Estas realidades son evidentes en la propiedad y el manejo de la infraestructura y tratamiento del agua, sobre las cuales los estados australianos han retenido la responsabilidad principal. Los aspectos operacionales del suministro de agua son controlados por las Corporaciones de Propiedad del Gobierno (Government Owned Corporations [GOC]), reestructuradas para parecer y actuar como compañías privadas (en preparación para su privatización total, sugieren algunos) (Strang 2009). Tal como en Estados Unidos, también se ha presentado un significativo cambio hacia las alianzas público-privadas, y hoy "el sector privado es crucial, con las firmas privadas que satisfacen una proporción cada vez mayor de las necesidades del sector" (AWA 2013, 21). Tales alianzas son comunes en la construcción de grandes esquemas de retención de agua, que también están destinadas a proporcionar mitigación de las inundaciones ${ }^{20}$.

Más recientemente, los esquemas de reciclaje y desalinización han pasado a primer plano. Aunque presentados en términos de seguridad del agua y de responsabilidad ecológica, estos son en parte una respuesta a poderosos grupos agrícolas e industriales en espera de que las aguas residuales (más baratas) sean recicladas para su uso en el riego y que las áreas urbanas -que tienen prioridad para el suministro de agua - sean abastecidas con aguas desalinizadas. Con un costo de más de 2.500 millones de dólares australianos (AUD), recientemente

Como lo mostraron las grandes inundaciones regulares en el sureste de Queensland, la infraestructura de mitigación de las inundaciones tiene un valor discutible en un paisaje propenso a los desbordamientos repentinos de los ríos. 
Queensland construyó un Esquema de Reciclaje para el Corredor Occidental que suministra mucha del agua necesaria para la generación de energía alrededor de Brisbane, reduciendo así el uso del agua de la Represa de Wivenhoe, que suministra riego a los agricultores dentro de su cuenca (Water Technology Net 2015). Tales desarrollos infraestructurales a gran escala involucran cada vez más a corporaciones transnacionales: este esquema fue construido por Veolia, que continúa teniendo la responsabilidad de la operación de las plantas y tuberías. Veolia (originalmente Vivendi) tiene operaciones en más de 60 países y recientemente anunció ingresos anuales de 23.800 millones de euros (Veolia 2015). Al mismo tiempo, las compañías de agua australianas han empezado a operar transnacionalmente: tal como lo expresa la Asociación de Agua Australiana, "existe una demanda internacional de la experticia del sector de agua australiano y las compañías australianas están activas alrededor del mundo" (AWA 2013, 5) ${ }^{21}$.

Otro desarrollo clave en las relaciones del agua y el poder australianos ha sido la introducción del comercio del agua, descrito por Caldecott (2008) como "privatización furtiva” (10). Esto les permite a los agricultores vender asignaciones de agua de una reserva común anteriormente distribuidas por el Estado, así como reformular y mercantilizar el agua como un "activo", lo que ha separado al agua de la tierra, de manera que en teoría (y cada vez más en la práctica) un agricultor necesitado puede vender el agua de su tierra, dejando como resultado una "parcela seca". Este comercio depende de un mercado virtual más que físico, que da lugar a la separación de la actividad económica de su ambiente social y material (Ladson y Finlayson 2004; Young y McColl 2004)22. La ruptura de la conexión inmediata entre la extracción de agua y sus impactos en los ecosistemas ha exacerbado los problemas de larga duración en el mantenimiento de suficientes "flujos ambientales" para la viabilidad de los humedales y de otros hábitats acuáticos; así mismo, ha creado grandes tensiones entre extractores río arriba y los agricultores aguas abajo. Dado que los grandes ríos australianos también están notoriamente sobreasignados, la reaplicación de licencias latentes de extracción se ha sumado al problema en la medida en que sus ventajas comerciales han crecido.

21 Por ejemplo, Transfield Services tiene más de 28.000 empleados en Australia, Nueva Zelanda, Estados Unidos, los Emiratos Árabes Unidos, Catar, Nueva Caledonia, el Sudeste Asiático, India, Chile y Canadá. GHD opera en Australia, Estados Unidos, México, África y Oriente Medio.

22 Mercados virtuales semejantes se han creado con cuotas de pesca, con efectos no muy diferentes (Minnegal y Dwyer 2010). Estos activos virtuales desafían la afirmación de Godelier (1986) de que la propiedad no es real si no es concreta. 
Para proteger sus intereses, los agricultores y otras industrias con frecuencia resaltan su papel central como "productores primarios” en la economía nacional y, así mismo, han elaborado un discurso de larga data sobre el "bien común” alcanzado por tal producción. Reclaman simultáneamente ser protectores del bienestar ecológico como "guardianes de la Tierra”, pero la continua intensificación de sus actividades económicas y la falta de progreso en la rehabilitación de ecosistemas que enfrentan dificultades sugieren que esta custodia se dirige principalmente hacia intereses específicos, muchos de los cuales no son locales: la producción agrícola en Australia está enfocada principalmente hacia los mercados extranjeros, y mientras estos pueden enriquecer a algunos agricultores y sostener una economía nacional, también ejercen presiones considerables para la intensificación de una agricultura altamente competitiva. Muchos agricultores reconocen que esto los obliga a adoptar prácticas insostenibles pero, como dicen, “es duro ser verde si estás en saldo en rojo” (Strang 2009, 129).

Esencialmente, en Australia hay tres maneras a través de las cuales se gana el control material sobre el agua: la adquisición de tierra, la adquisición de asignaciones de agua y la capacidad de construir infraestructura que dirija el agua hacia intereses particulares. Tal como en el Reino Unido, cada una de estas está sujeta a la reglamentación gubernamental diseñada para limitar los impactos sociales y económicos negativos, pero tales limitaciones son secundarias frente a un compromiso nacional con el crecimiento económico. En cada una de estas formas de control del agua ha habido una expansión de la propiedad extranjera (en general corporativa) y esto ha sido activamente impulsado por el sector agrícola, dirigido por AgForce, su grupo de cabildeo más importante. En sus comentarios al informe del gobierno federal llamado "Fortalecimiento de la inversión extranjera en Australia (documento de opciones)”, los representantes de AgForce para Queensland declararon que:

En Queensland, la inversión extranjera ha sido durante mucho tiempo una característica de la agricultura, y ha contribuido significativamente al desarrollo económico de las agroindustrias de amplio espectro en el Estado. Dada la necesidad de impulsar un mayor crecimiento económico, AgForce tiene mucho interés en que haya una inversión extranjera en la agricultura de manera abierta y transparente y en línea con nuestros intereses nacionales [...] Nuestra postura frente a la política pública es que no nos oponemos a la inversión extranjera motivada comercialmente por este tipo de agricultura. $(2015,1)$

Otros grupos de productores primarios, incluida la Federación Nacional de Agricultores (National Farmers' Federation [NFF]), también han apoyado la inversión extranjera. Los grupos conservacionistas y ambientalistas estuvieron 
notoriamente ausentes en la lista de las 192 respuestas formales al informe gubernamental, aunque en otros foros muchos han sido críticos de esto y del uso excesivo del agua (Strang 2009). Sin embargo, uno de los puntos con el cual muchos de estos grupos están de acuerdo con AgForce y el NFF es el apoyo a un llamado para que se realice un registro nacional de la propiedad de las asignaciones de agua:

Un registro nacional de propiedad extranjera de tierras y de agua es un paso fundamental para responder a las preocupaciones de la comunidad respecto de la inversión en la agricultura australiana. El registro deberá proporcionar una base de datos robusta y rigurosa que pueda usarse para monitorear e informar sobre las tendencias y desarrollos que pudieran tener un impacto en la cadena de suministro agrícola en Australia. (NFF 2015, 1)

Todas las partes reconocen que este es un asunto de poder: "Australia es un continente árido, y los recursos de agua son un elemento increíblemente importante para una agricultura productiva y rentable en nuestro país. Las asignaciones de agua comerciables conllevan un control significativo del potencial productivo" (AgForce 2015, 2).

El llamado a realizar un registro nacional ha recibido impulso debido al rápido aumento de la propiedad extranjera, tanto de la tierra como del agua. Desde 1988, Queensland ha mantenido un registro de tierra estatal que ilustra esta expansión. En el 2003, "los intereses extranjeros de propiedad sobre la tierra sumaron un total de 1.673.245 ha, y representaron un 0,96\% de la superficie terrestre del estado”, y había 127 países de origen registrados en la base de datos (ABS 2003b). Para el 2012, el porcentaje había aumentado a 2,9\% y para el 2013, a 3,2 \%. En el 2015 los intereses extranjeros sobre la propiedad de la tierra en Queensland (para todos los usos) sumaron un total de 5.881.300 ha, que representan solo un $3,4 \%$ de la superficie del estado, y había 133 países de origen inscritos en el registro (ABS 2015b). Un estudio sobre la propiedad de la tierra para la agricultura, así como del agua, observó que, “en Australia, la mayoría de la propiedad extranjera de la tierra para la agricultura sigue en manos de grandes empresas; menos de 50 empresas son propietarias del 95\% del área total” (ABS 2014b).

En Queensland, una parte de la inversión de las corporaciones internacionales ha incluido la compra de grandes estancias ganaderas, pero en Nueva Gales del Sur, en particular, el enfoque principal de dicha inversión ha sido la adquisición de tierras agrícolas irrigadas, así como de asignaciones de agua ${ }^{23}$. 
A lo largo de toda Australia, los propietarios extranjeros tienen una participación de un 11,3\% del total de la tierra agrícola y han invertido alrededor de un 8,5\% de los derechos de agua para la agricultura [...] Los informes de ABS muestran que Nueva Gales del Sur consume la mayor cantidad de agua para la agricultura en Australia, seguido de cerca por Queensland [...] Casi dos tercios del uso total de agua para la agricultura en Australia se encuentran en la cuenca Murray-Darling. Los informes también muestran que el volumen de agua destinado a la tierra agrícola en la cuenca Murray-Darling se ha incrementado en un $26 \%$ con respecto a los niveles de 2009-2010. (Smith 2012,1)

Los gobiernos estatales en Australia han continuado entregando a los agricultores y, en particular, a las grandes compañías de irrigación, licencias para la concesión de agua. En el 2014, “11,3 megalitros fueron totalmente propiedad de australianos, mientras que 1,8 millones de megalitros tenían alguna proporción de propiedad extranjera, un incremento del 55\% sobre la proporción de propiedad extranjera en el 2010” (ABS 2014, 1).

De manera crítica, dentro de los límites regulatorios sobre la altura de la represa, los irrigadores pueden construir sus propias estructuras para embalsar y almacenar el agua. Esto ha añadido un poder infraestructural considerable a las inversiones en la tierra y el agua. Por ejemplo, a principios de los 2000, a la notoria estancia Cubbie Station, en el límite de Queensland-Nueva Gales del Sur, se le permitió comprar más de 50 licencias de concesión de agua y construir una serie de embalses masivos con una extensión de $28 \mathrm{~km}$ a lo largo del río Culgoa, que irrigan un área de $40 \mathrm{~km}$ de ancho de campos de algodón y trigo. Estos embalses, tan grandes que pueden ser vistos desde el espacio, almacenan hasta 400 gigalitros de agua, equivalentes aproximadamente a dos tercios del consumo anual de agua de Sídney. Se llenan mediante un canal de desviación masiva que redirecciona cerca de una cuarta parte del agua que, de lo contrario, fluiría hacia la cuenca Murray-Darling, que ya está radicalmente en riesgo. Esto ha conducido a protestas por parte de grupos conservacionistas, agricultores y comunidades locales indignados por la pérdida de humedales y por las áreas agrícolas aguas abajo que se han visto privadas de agua. En el 2012, Cubbie Station fue comprado por un consorcio transnacional (Dickie y Brown 2007; Strang 2013).

Lo que surge, entonces, es un escenario en el que el uso intensificado del recurso y el aumento de la propiedad extranjera, así como el desarrollo

Nueva Gales del Sur, la tendencia es opuesta, los propietarios extranjeros tienen inversiones en solo un 2,7\% de la tierra dedicada a la agricultura, pero un 10,6\% de los derechos totales de agua del estado (Smith 2012, 1). 
infraestructural relacionado, se han combinado para desplazar sustancialmente el grado de control del agua de Australia hacia una élite transnacional. Es tentador concluir que la agencia de las comunidades locales humanas y no humanas se ha perdido literal y metafóricamente en el proceso.

\section{Flujos conflictivos de agua y poder}

Los dos casos de estudio se enfocan en áreas donde la tendencia ha sido hacia la propiedad y el control del agua privatizadas y cada vez más transnacionales. Esfuerzos similares se han llevado a cabo en otros lugares: en Nueva Zelanda, el comercio del agua fue introducido recientemente, y en el 2012 los maoríes perdieron una batalla jurídica para lograr el reconocimiento de sus derechos de propiedad del agua y para prevenir que el Gobierno vendiera acciones (y en consecuencia concesiones de agua) de grandes compañías de energía hidroeléctrica (Strang 2014c). La construcción de represas en Asia y Sudamérica con propiedad y manejo corporativo sigue reemplazando las formas tradicionales de control del agua (Shiva 2002).

Sin embargo, muchos de estos intentos se han topado con una tenaz oposición. A principios de los 2000, una "guerra del agua" en Bolivia repelió los intentos de Bechtel, una compañía estadounidense, de privatizarla (Albro 2005). En Nueva Zelanda, los iwis maoríes siguieron presionando por el reconocimiento de los derechos indígenas sobre el agua, y en el 2016 el tribunal Waitangi anunció que, a pesar del rechazo de la Corte Suprema, la segunda fase del reclamo del Consejo Maorí era procedente (Radio Nueva Zelanda 2016).

Existen contramovimientos que se hacen oír y que surgen a través de una multiplicidad de organizaciones a escala local, nacional e internacional, los cuales, insistiendo en las ideas de larga data del agua como un "bien común”, ven los derechos sobre el agua como un asunto central de la justicia social, ligados con debates más amplios sobre la colectividad y su empoderamiento político. Estas ideas están implícitas en la declaración del 2010 de las Naciones Unidas de que todos los seres humanos tienen el derecho "al agua limpia y potable y al saneamiento básico” (UN General Assembly 2010). Sin embargo, a pesar de haberse logrado algún progreso en este sentido, 663 millones de seres humanos todavía 
carecen del acceso de manera fiable a agua limpia y potable, y más del $30 \%$ de la población mundial no tiene instalaciones de saneamiento básico (Unicef 2015) ${ }^{24}$.

Las propuestas para solucionar este problema han tendido a evitar involucrarse con sus complejas e intricadas causas, tales como las presiones para el desarrollo intensivo y el uso excesivo de los recursos limitados de agua dulce, el desplazamiento de las comunidades locales y el cambio ambiental. En general, las soluciones que se han promovido, por ejemplo por McKinsey, todavía buscan lograr un mayor crecimiento económico, el uso y manejo más “eficiente” del recurso y “mejores” (i. e. más directos) métodos de captura y control del agua (Manyika et al. 2015).

Dado que la infraestructura del agua suple la materia generativa de la vida, tal como la producción de comida, es difícil verla de otra manera que no sea en términos positivos. Las representaciones de las organizaciones de cooperación internacional están llenas de imágenes de nuevos pozos y niños felices salpicándose con agua limpia y centelleante. En estas imágenes es invisible una realidad subyacente a la organización Water Aid, pues, aunque suministra beneficios genuinos e inmediatos a algunas comunidades, está en gran medida financiada por la industria del agua del Reino Unido. Según los empleados de las compañías de agua, una de sus actividades más rentables es el mercadeo internacional de la experticia en la privatización del agua y la construcción de infraestructura (Strang 2004). El objetivo no es solamente asegurar una actividad suplementaria rentable sino ensanchar de manera más general los mercados internacionales de agua. Por ejemplo, en 1998, Wessex Water, comprada por Asurix (de propiedad de Enron) y después en el 2010 vendida al grupo de energía malasio YTL, ha enviado a múltiples expertos a Centroamérica. Thames Water ha provisto al Gobierno australiano con una cantidad de asesores: comprada por la compañía alemana RWE poco después de haber sido privatizada, fue vendida en el 2006 a un consorcio dirigido por el banco australiano Macquarie, que tiene intereses en aproximadamente 80 compañías en el mundo entero. Estos esfuerzos para ampliar el mercado internacional de agua no han sido exitosos del todo (Christine Bichsel, comunicación personal). No obstante, han involucrado a compañías en el mercado de agua en muchos países, posibilitándoles ganar un control significativo sobre algunos (tal como en Inglaterra y Australia), y han creado un naciente mercado internacional del agua.

\footnotetext{
24 "En 2015, 663 millones de personas aún carecen de fuentes mejoradas de agua potable, 2.000 millones carecen de instalaciones de saneamiento mejoradas y 946 millones todavía practican la defecación al aire libre" (Unicef 2015).
} 
Tal como lo han puesto de manifiesto los antropólogos que estudian la ayuda y el desarrollo, a menudo tales actividades se apoyan en premisas de que el crecimiento económico es el resultado deseado y el gran objetivo es crear nuevos mercados y lograr acceso a los recursos. Sus análisis han destacado el potencial que tienen las actividades de desarrollo tanto altruistas como egoístas para producir nuevas formas de colonialismo económico (Arce y Long 1999; Mosse y Lewis 2005). Las infraestructuras financiadas y construidas por las compañías del agua y las organizaciones de desarrollo no solo llevan agua sino también ideas, valores y prácticas, y posibilitan crear vínculos entre los expertos de la industria y los actores políticos poderosos, lo que sirve para apoyar regímenes nacionales e internacionales específicos de gobernanza y manejo del agua.

\section{Asuntos bioéticos}

La falta de agua disponible para algunas poblaciones humanas plantea dilemas particulares a los contramovimientos que intentan defender los derechos de las especies no humanas y del ambiente material ${ }^{25}$. Aunque tanto los activistas ecológicos como los de justicia social enmarcan sus inquietudes en términos de derechos, sus reclamos no son siempre compatibles. Los grupos preocupados por el suministro de agua a comunidades humanas más desfavorecidas pueden estar buscando desarrollos infraestructurales que les quitan agua a los ecosistemas y a sus especies no humanas dependientes, de manera que los grupos conservacionistas han sido críticos de tales esquemas ${ }^{26}$.

Es obvia la dificultad para tener una visión crítica de la infraestructura de agua que provee el suministro a las comunidades desfavorecidas. No obstante, una dificultad similar también desalienta las prácticas ecológicas en las sociedades ricas, ya que, debido a que el agua tiene significados positivos tan poderosos en las distintas culturas debido a su capacidad generativa, de salud y de bienestar, los flujos generosos de agua están casi sin excepción vinculados

25 Por ejemplo, Personas por el Trato Ético de los Animales (People for the Ethical Treatment of Animals), la Liga para la Defensa de los Animales (Animal Defense League), la Liga Humanitaria (Humanitarian League), el Movimiento por los Derechos de los Animales de Finca (Farm Animal Rights Movement). reconciliar, sobre la conservación, en los que los derechos de los animales (o los derechos de unas pocas personas que se benefician del turismo) frecuentemente entran en conflicto con los derechos e intereses de propietarios de tierra tradicionales (Homewood 2015). 
simbólicamente a la riqueza y el estatus, a la seguridad y, desde luego, al poder y la agencia (Strang 2004, 2009). Pero tales premisas también tienden a darles primacía a los intereses humanos y menos prioridad al impacto de esa infraestructura en las especies no humanas.

Estas preocupaciones están lejos de ser nuevas: surgieron de las ansiedades románticas sobre el bienestar de la naturaleza que ganaron impulso en los años sesenta y setenta como parte de los poderosos movimientos de justicia social en los que las feministas y otros activistas mostraron la ampliación de las desigualdades humanas y no humanas. Por otro lado, desde esa época el movimiento verde se ha fragmentado y desconectado cada vez más de las organizaciones preocupadas por los derechos humanos, y ha sido “adoptado” por los intereses gubernamentales y corporativos, sometido a la autoridad científica y desradicalizado de manera significativa (Berglund 1998; Doherty 2002; Greer y Bruno 1996; Milton 1993). Con la excepción del activismo interesado específicamente en los derechos de los animales y de organizaciones atípicas como Greenpeace, pocas organizaciones conservacionistas elaboran discursos explícitos sobre los derechos de los no humanos o sobre la política de anularlos.

Entonces, seamos claros. Todas las infraestructuras del agua tienen impactos directos sobre los ambientes materiales y sus habitantes no humanos. Hasta qué punto estas infraestructuras ignoran las necesidades de los no humanos y desvían el agua para sostener a las comunidades humanas, en vez de sostener el bienestar de los no humanos, es una medida directa de las relaciones entre los mundos humano y no humano. Los compromisos societarios con el agua que se ajustan a las necesidades de los seres no humanos o les otorgan posiciones agentivas y algún grado de igualdad social y política son extremadamente raros hoy en día. Tal como lo demuestran los patrones de cambio en la propiedad y el control del agua, la evolución de estos cambios ha ido en gran medida en la dirección opuesta, es decir, hacia una división dualista entre los humanos y los otros; hacia arreglos sociales y políticos jerárquicos, ratificados por infraestructuras que afirman la agencia humana; y hacia cosmologías que reflejan estas ideas y prácticas. Después de siglos de “dominio” humano, que ha culminado en una exitosa promoción global de modos de involucramiento ambiental cortoplacistas y claramente no sostenibles, con frecuencia los enfoques alternativos son presentados como románticos, quijotescos y sobre todo no realistas, y aun los debates serios sobre el decrecimiento económico tienen que responder a estas categorizaciones y rechazarlas (Daly 1996; Harvey 2010; Jessop 2012).

Sin embargo, no puede ser más realista persistir con prácticas orientadas hacia el crecimiento que han producido niveles de cambio ambiental que 
amenazan la existencia, una tasa de extinción masiva de especies igualada previamente solo por grandes crisis planetarias, crecientes niveles de privación humana y múltiples conflictos sociales y políticos. El cambio solo puede ocurrir si es tanto conceptual como social y material, y esto significa lidiar con los desafíos de la dinámica histórica de largo plazo en cada una de estas áreas.

\section{Cambio cosmológico}

En la antropología, los esfuerzos para elaborar nuevas maneras de conceptualizar las relaciones humanas-ambientales han llevado a un diálogo útil con la filosofía sobre la bioética y la necesidad de considerar la agencia, tanto de los seres no humanos como de las cosas. Esto se basa en etnografías multiespecies que examinan interacciones humano-animales (Haraway 2008; Kirksey y Helmreich 2010) e investigaciones con contramovimientos sociales y ambientales (Berglund 1998; Milton 1993). También son relevantes las teorías sobre la cultura material (Boivin 2008; Knappett y Malafouris 2008; Tilley et al. 2006) y, de manera más general, sobre las relaciones materiales (Bennett 2009; Coole y Frost 2010). Esta confluencia de ideas ha ayudado a incentivar nuevas teorías que abarcan integralmente a seres humanos y no humanos, así como objetos y procesos materiales (Strang 2018; Tsing 2004).

Los antropólogos también tienen la ventaja de trabajar con comunidades culturales diversas, cuyos sistemas de creencias cosmológicas pueden no ajustarse a las visiones predominantes sobre las relaciones humanas-no humanas. Las cosmovisiones y las relaciones de las comunidades indígenas con "el otro" no han sido simplemente la inspiración para muchos grupos ambientalistas, sino que han contribuido sustancialmente al desarrollo de la teoría antropológica y su capacidad para imaginar múltiples maneras de vivir y alternativas frente a las normas dominantes (Hirsch y Strathern 2004; Strang 2006). Por consiguiente, las teorías indígenas y antropológicas se combinan de manera útil para promover una crítica a los supuestos humanos del dominio y a la reducción mercantilizante del mundo no humano a un conjunto de activos materiales. Quizás el elemento más trascendental es que presentan maneras de reintegrar formas fragmentadas de pensar los procesos sociales, económicos y ecológicos, y proveen un puente que cruza la brecha intelectual entre las ciencias sociales y naturales. 


\section{Cambio social y político}

Si las sociedades reconstituyeran maneras de pensar que no separan la actividad económica de los procesos sociales y ecológicos, tal reintegración conceptual demandaría su expresión en arreglos políticos y materiales. Abordaría, por ejemplo, la crucial separación estructural entre las agencias responsables de apoyar las actividades económicas y aquellas enfocadas en proteger el bienestar ecosistémico, separación que permite que los costos de las actividades económicas sean externalizados a los seres no humanos. Produciría legislación integradora y mecanismos regulatorios correspondientes, y revelaría la separación entre los intereses económicos y sociales (humanos), y los sistemas ecológicos (no humanos) y los habitantes de estos sistemas, como una priorización desigual de derechos e intereses.

\section{Una desconexión crítica}

Las infraestructuras del agua pueden expresar múltiples formas de agencia, que incluyen la de distantes corporaciones transnacionales y sus accionistas. En un mundo de mercados de agua abstractos y de propiedad de compañías de irrigación y de agua que pertenecen a no residentes, las redes internacionales de élites que se benefician del control del agua dulce de la tierra a menudo son distantes geográficamente de los ecosistemas de donde se extrae el agua ${ }^{27}$. También son distantes de las economías locales y son capaces de evadir el pago de impuestos en los países donde generan ganancias considerables. Por ejemplo, en el 2013 hubo una indignación generalizada cuando Thames Water eludió pagar cualquier impuesto sobre sociedades en el Reino Unido, a pesar del aumento de las tarifas de agua en 6,7\%, ingresos de 1.600 millones de liras y utilidades operativas de 549 millones de liras ("Thames Water Paid no UK Corporation Tax for the Year” 2013). Por supuesto que esto resuena con la perspectiva clásica de Karl Polanyi (1944) sobre cómo los mercados crean un proceso de "disociación” (disembedding) y el creciente reconocimiento de que las fuerzas del mercado no son la panacea imaginada por la utopía neoliberal (Dale 2010). 
La perspectiva de Polanyi implica que la falta de una ubicación compartida y de una participación inmediata desconecta a los miembros del consorcio internacional de los intereses de los residentes locales, tanto humanos como no humanos. Granovetter (1985), en contraste, afirma que la acción económica está enraizada en las relaciones sociales y que "la mayor parte del comportamiento está estrechamente incrustado en las redes de relaciones interpersonales” (504). Sin embargo, ambos pueden tener razón. Las corporaciones transnacionales no funcionan fuera de las relaciones sociales: por el contrario, son redes sociales extremadamente efectivas, pero operan de manera al menos semiindependiente, fuera de los países (y sociedades) cuya agua controlan. Así tengan intenciones altruistas o simplemente sean interesadas, están desconectadas, tal como los generales muy lejos de las líneas de batalla, que ejercen control sin consecuencias personales. Sus acciones están en cierta medida limitadas por las condiciones locales, tanto materiales como sociales, pero a fin de cuentas deciden dónde y cómo se dirigen los flujos de agua y quién (o qué) se beneficia o carga con los costos derivados de estas decisiones. En este sentido, las redes sociales internacionales a las que pertenecen estas corporaciones constituyen un nuevo "régimen despótico”, es decir, un centro de poder transnacional que tiene una considerable capacidad para afectar vidas humanas y no humanas sin rendir cuentas.

Esto da lugar a una pregunta relacionada sobre el agua y el poder que he planteado en otro escrito (Strang 2011). ¿Si la propiedad del agua y de otros recursos materiales esenciales, y los medios infraestructurales para manejarlos, no son poseídos democráticamente por el Estado, a quién le pertenece el Estado? ¿Cómo ejerce el poder el Estado? ¿Acaso existe el Estado? Walker (2014) nos recuerda que "el Estado, como coordinador de la acción colectiva y como un intermediario entre las esferas pública y privada, ha cambiado significativamente en su naturaleza" (390), y lo describe como un cambio de gobierno a gobernanza (véase Tortajada 2010). Este punto también es destacado por Stiglitz (2002) en su trabajo sobre la globalización, en el que señala el potencial de la gobernanza global sin gobierno global.

Esta gobernanza se lleva a cabo principalmente mediante la legislación, e incluye las leyes nacionales e internacionales que teóricamente defienden los derechos básicos de las personas al agua y a proteger el ambiente, así como las disposiciones reglamentarias que hacen respetar estos principios a escala nacional. Sin embargo, tanto la legislación internacional como la nacional han mostrado ser inefectivas para alcanzar estos objetivos. Como se anotó previamente, millones de personas carecen de acceso al suministro de agua y al saneamiento básico; las tarifas de agua en países donde la industria de suministro de agua ha sido 
privatizada se han incrementado de manera invariable y radical, y en toda Europa menos de un 1\% de los ríos cumplen con los estándares de la Directiva Marco del Agua de la Unión Europea de 2000 (European Environment Bureau 2010).

En consecuencia, no sorprende que la adquisición de las compañías de suministro de agua y de irrigación por parte de corporaciones transnacionales siga generando preocupación. Junto con las ansiedades sobre los impactos sociales y ecológicos, la entrega del control del agua a las corporaciones transnacionales, y más generalmente al "mercado", ha contribuido a plantear cada vez más dudas sobre la democracia en sí, es decir, sobre hasta qué punto los gobiernos (de cualquier tendencia política) son representativos “de” sus poblaciones o capaces de proteger los intereses humanos y no humanos. Estas preocupaciones se expresan en las protestas contra la privatización, en batallas por los derechos al agua, y en las demandas para que los gobiernos registren y monitoreen toda propiedad extranjera de la tierra y los recursos.

\section{Conclusión}

Lo que surge, entonces, es un escenario bastante alarmante donde el agua y el poder se están alejando de las sociedades, hacia arriba y hacia afuera en dirección de un régimen transnacional, en gran parte antidemocrático y potencialmente “despótico” que no rinde cuentas y es intocable. Al retener el agua y otros recursos claves, las redes internacionales que tienen vínculos económicos y sociales y una ideología compartida están bien ubicadas para influenciar gobiernos nacionales y, hasta cierto punto, volverlos impotentes. Mientras tanto, el cinismo y una sensación de incapacidad de efectuar algún cambio han reducido radicalmente la disposición de la población de limitar su propio uso del recurso y proteger los bienes comunes.

Las infraestructuras en sí mismas son ineludiblemente locales y materiales, concretan y perpetúan ciertos valores y creencias y las prácticas que los expresan. No son inmediatamente deconstruidas, y por consiguiente son intrínsecas a la dinámica histórica, pero, como se señaló antes, las infraestructuras -y el agua - como cualquier forma de cultura material, tienen vidas sociales en las que sus significados y usos pueden cambiar (Wagner 2013). Al conducir lo que muchas personas ven como la sustancia de la vida en sí misma, proporcionan un foco para la acción social y política, y pueden estar sujetas a un "régimen despótico”. Sin embargo, también pueden sustentar los deseos de cambiar los arreglos políticos y las relaciones humanas y no humanas que estos conforman. 
El poder del consumidor es un potencial desaprovechado. En un sentido más amplio, tener el control del agua es en parte un asunto de tener el poder adquisitivo para comprar los alimentos y otros productos que la contienen. Mientras que los debates sobre la propiedad del agua se enfocan en la infraestructura y el suministro, es importante recordar que las sociedades ricas a menudo dependen fuertemente de bienes importados y por tanto del agua que contienen, proveniente de países más pobres (Allan 2011). El agua en áreas áridas se usa para producir bienes que requieren gran cantidad del líquido, los cuales serán enviados a mercados en climas más templados. Por ejemplo, los usuarios alemanes de agua tienen una huella internacional del agua que se extiende por cuatrocientos países diferentes (Meissner 2012; véase también Hoekstra y Chapagain 2007). Como lo señala Wichelns (2015), mapear los flujos de agua entre diferentes lugares del mundo excluye las complejidades de la ventaja comparativa, que es "un principio fundamental de la teoría del comercio” (397), así como las muchas variables que determinan "el uso óptimo de la tierra y los recursos” (401). No obstante, los consumidores están implicados en un proceso que mueve el agua alrededor del mundo y que apuntala regímenes específicos de propiedad y suministro del agua. Esto también significa que, al modificar sus patrones de consumo, los consumidores tienen alguna capacidad de influenciar la gobernanza del agua y sus regímenes de uso.

Como se expuso al inicio, existen muchas maneras subalternas de propiedad y apropiación del agua. Las comunidades locales y los grupos de manejo de distintas cuencas pueden trabajar directamente con el ambiente físico así como hacer campañas para un mejor manejo del agua. Expertos, con la autoridad que les confiere el conocimiento especializado, pueden participar en la toma de decisiones sobre desarrollos infraestructurales. Los contramovimientos y los usuarios del agua pueden hacer lobby en pro de nuevos arreglos políticos y materiales, y aunque de ninguna manera yo lo aprobaría, la vulnerabilidad de las grandes infraestructuras del agua los hace un objetivo obvio para acciones políticas radicales, y esta posibilidad es algo que los formuladores de política pública definitivamente deben considerar en la medida en que las poblaciones están cada vez más insatisfechas con su falta de voz y voto.

Existe un potencial para que estos contramovimientos se unan lo suficiente para restablecer la propiedad y el control compartido del agua. No podemos asumir que estas comunidades necesariamente vayan a adoptar prácticas sociales y ecológicas más sostenibles. Aun las sociedades de pequeña escala, de base local, son capaces de colapsar, y la historia está plagada de ejemplos de patrones de crecimiento no sostenibles (Diamond 2005). Sin embargo, también existen 
ejemplos de regímenes duraderos de propiedad común (Godden y Tehan 2010; Ostrom 1990, 2010), y tales arreglos tienen la ventaja significativa de que todos los actores participan y dan lugar a un resultado compartido.

También hay importantes preguntas en cuanto a si es posible regular efectivamente un mercado global. Tal como uno de los evaluadores de este artículo comentó, la reubicación de la propiedad y el control no son la única solución posible, y hay muchas otras maneras de "imponer el reconocimiento de la responsabilidad en las largas cadenas de valor”. El desempeño de la Directiva Marco sobre el Agua de la Unión Europea no es alentador y los debates actuales sobre la Unión muestran los desafíos que se presentan al tratar de extender las nociones de comunidad mas allá de las fronteras nacionales, aunque esto no significa que estos esfuerzos deban ser abandonados.

Sin embargo, las leyes median las relaciones entre las personas, y entre las personas y las cosas, y necesitan poder expresarse en términos materiales. Por lo tanto, la legislación a escala internacional se debe basar en una comprensión real de las complejas relaciones materiales a través de las cuales los derechos e intereses (humanos y no humanos) se cumplen a escala local. Sin al menos propiedad y control del agua nacionales, es difícil ver cómo un régimen legislativo internacional pudiera comprometerse lo suficiente con realidades sociales y materiales locales, y en el presente carecemos de mecanismos lo suficientemente efectivos para ejercer la democracia a escala global. Tal vez unas Naciones Unidas mucho más fuertes, en combinación con un control democrático del recurso en las escalas nacional y local, puedan ofrecer un mejor resultado que aquel provocado por fuerzas políticas más volátiles.

Entonces, existen múltiples formas de propiedad y control del agua que tienen algún potencial para cambiar la manera como se usa y maneja. Qué tanto puedan estas efectuar un cambio político y material genuino, y por lo tanto reformar las relaciones humanas-no humanas, está por verse, y los humanos no poseemos todas las cartas. A fin de cuentas, el ambiente en sí mismo, de manera imparcial e inexorable, continuará respondiendo a las expresiones humanas de agencia y poder a través del agua: si estas son insostenibles, simplemente dejarán de ser sostenidas.

Traducido por Andy Klatt

Traductor certificado en Estados Unidos y traductor oficial en Colombia andy.klatt@gmail.com María Clemencia Ramírez Antropóloga e investigadora honoraria del ICANH clema15@yahoo.com 


\section{Referencias}

AgForce. 2015. "Submission on the Strengthening Australia's Foreign Investment Framework Options Paper”. AgForce Queensland, Brisbane. www.treasury.gov.au/ /media/Treasury/Consultations\%20and\%20Reviews/Consultations/2016/National\%20register \%20 water\%20access\%20entitlements/Submissions/PDF/AgForce.ashx.

Albro, Robert. 2005. “The Water is Ours, Carajo! Deep Citizenship in Bolivia's Water War”. En Social Movements. An Anthropological Reader, editado por June Nash, 249-268. Londres: Blackwell.

Alexander, Catherine. 2004. "Value, Relations and Changing Bodies. Privatization and Property Rights in Kazakhstan”. En Property in Question. Value Transformation in the Global Economy, editado por Katherine Verdery y Caroline Humphrey, 251-273. Oxford; Nueva York: Berg.

Allan, Tony. 2011. Virtual Water. Tackling the Threat to our Planet's most Precious Resource. Londres: I. B. Tauris.

Altman, Jon. 2004. “Indigenous Interests and Water Property Rights”. Dialogue 23 (3): 29-34.

Anand, Nikhil. 2012. "Municipal Disconnect: On Abject Water and its Urban Infrastructures”. Ethnography 13 (4): 487-509.

Appadurai, Arjun. 1986. The Social Life of Things. Commodities in Cultural Perspective. Cambridge: Cambridge University Press.

Arce, Alberto y Norman Long, eds. 1999. Anthropology, Development, and Modernities. Exploring Discourses, Counter-Tendencies, and Violence. Londres: Routledge.

Attwood, Bain y Andrew Markus. 1999. The Struggle for Aboriginal Rights. A Documentary History. St. Leonards, New South Wales: Allen \& Unwin.

Australian Bureau of Statistics (ABS). 2003a. Environmental Impact of Agriculture, Canberra: ABS. www.abs.gov.au/ausstats/abs@.nsf/46d1bc47ac9d0c7bca256c470025ff87/3319eb4 d2d14bd2dca256cae0015 bad3!OpenDocument.

-. 2003b. Annual Report on Administration of Foreign Ownership of Land Register Act 1988. Canberra: ABS.

-. 2005. Water Use on Australian Farms 2002-03. Canberra: ABS. www.abs.gov.au/AUSSTATS/ abs@.nsf/allprimarymainfeatures/E780C7632FC1A867CA2570A600763E5E?opendocument.

- . 2014a. Water Use on Australian Farms 2012-13. Canberra: ABS. www.abs.gov.au/AUSSTATS/ abs@.nsf/allprimarymainfeatures/F21596640D138568CA257E53001C8C30?open document.

- .2014b. Agricultural Land and Water Ownership. Canberra: ABS. www.abs.gov.au/ausstats/ abs@.nsf/mf/7127.0.

—.2015a.Salinity. Canberra: ABS.www.abs.gov.au/ausstats/abs@.nsf/Lookup/by\%20Subject /1370.0 2010 Chapter Salinity\%20.

-. 2015b. Annual Report 2014-2015 on Administration of Foreign Ownership of Land Register Act 1988. Canberra: ABS. 
Australian Water Association (AWA). 2013. Australia's Dynamic Water Industry. Canberra: AWA; Australian Trade Commission.

Bakker, Karen. 2003. An Uncooperative Commodity. Privatizing Water in England and Wales. Nueva York: Oxford University Press.

-. 2005. "Neoliberalizing Nature? Market Environmentalism in Water Supply in England and Wales”. Annals of the Association of American Geographers 95 (3): 542-565.

Barber, Marcus, Sue Jackson, Jeffrey Dambacher y Marcus Finn. 2015. "The Persistence of Subsistence: Qualitative Social-Ecological Modeling of Indigenous Aquatic Hunting and Gathering in Tropical Australia”. Ecology and Society 20 (1): 60.

Bennett, Jane. 2009. Vibrant Matter. A Political Ecology of Things. Durham, NC: Duke University Press.

Berglund, Eeva K. 1998. Knowing Nature, Knowing Science. An Ethnography of Environmental Activism. Knapwell, Cambridge: The White Horse Press.

Biodiversity Action Group (BAG). 1996. High and Dry. The Impacts of Over-Abstraction of Water on Wildlife. Londres: Biodiversity Challenge.

Biswas, Asit K. 1970. History of Hydrology. Ámsterdam; Londres: North-Holland Publishing Company.

Boivin, Nicole. 2004. "From Veneration to Exploitation. Human Engagement with the Mineral World”. En Soil, Stones and Symbols, editado por Nicole Boivin y Mary Ann Owoc, 1-30. Londres: UCL Press.

-. 2008. Material Cultures, Material Minds. The Impact of Things on Human Thought, Society and Evolution. Cambridge; Nueva York: Cambridge University Press.

British Government. 1918. "Representation of the People Act 1918”. Parliamentary Archives, HL/PO/PU/1/1918/7\&8G5c64. www.parliament.uk/about/living-heritage/transformingso ciety/electionsvoting/womenvote/parliamentary-collections/collections-the-vote-andafter/representation-of-the-people-act-1918/.

-. 1928. "Representation of the People (Equal Franchise) Act 1928”. Parliamentary Archives, HL/PO/PU/1/1928/18\&19G5c12. www.parliament.uk/about/livingheritage/transforming society/electionsvoting/womenvote/parliamentary-collectionsdelete/equal-franchiseact-1928/.

Builth, Heather. 2002. "The Archaeology and Socioeconomy of the Gunditjmara. A Landscape Analysis from South-West Victoria, Australia”. Tesis de Doctorado en Arqueología y Antropología, Flinders University, Adelaide, Australia.

Butzer, Karl. 1976. Early Hydraulic Civilisation in Egypt. A Study in Cultural Ecology. Chicago; Londres: University of Chicago Press.

Caldecott, John. 2008. "National Water Market. Privatisation on the Murray Darling”. Australian Options Magazine 54: 9-13.

Carneiro, Robert L. 1970. "A Theory of the Origin of the State”. Science 169: 733-738.

Castree, Noel. 2010. "Neoliberalism and the Biophysical Environment. What 'Neoliberalism' Is, and What Difference Nature Makes to It”. Geography Compass 4 (12): 1725-1733. 
Coles, Anne y Tina Wallace, eds. 2005. Water, Gender and Development. Oxford; Nueva York: Berg.

Coole, Diana y Samantha Frost, eds. 2010. New Materialisms. Ontology, Agency and Politics. Durham, NC; Londres: Duke University Press.

Council of Australian Governments (COAG). 2004. "Meeting Report”. 25 de junio. www. coag.gov.au/meetings/250604/index.htm.

Dale, Gareth. 2010. Karl Polanyi: The Limits of the Market. Cambridge: Polity Press.

Daly, Herman. 1996. Beyond Growth. Boston: Beacon Press.

Department for Environment, Food and Rural Affairs (Defra). 2014. Water Bill Upstream Competition and Abstraction Reform. March 2014. Londres: Defra.

Diamond, Jared. 2005. Collapse: How Societies Choose to Fail or Succeed. Nueva York: Viking.

Dickie, Phil y Susan Brown. 2007. “The Rise and Rise of Cubbie Station”. Melaleuca Media. www.melaleucamedia.com.au/01_cms/details.asp?ID=257.

Doherty, Brian. 2002. Ideas and Actions in the Green Movement. Londres: Routledge.

Durkheim, Émile. 1961. The Elementary Forms of the Religious Life. Nueva York: Collier Books.

Edgeworth, Matt. 2011. Fluid Pasts: Archaeology of Flow. Londres: Bloomsbury Academic Press.

English Nature. 1996. Impact of Water Abstraction on Wetland SSSIs. Peterborough: English Nature.

European Environmental Bureau. 2010. 10 Years of the Water Framework Directive: A Toothless Tiger? Bruselas: European Environmental Bureau.

European Parliament. 2000. Water Framework Directive (2000). Bruselas: European Parliament.

Ferguson, Diana. 2000. Tales of the Plumed Serpent: Aztec, Inca and Mayan Myths. Londres: Collins \& Brown.

Foucault, Michel. 1972. The Archaeology of Knowledge and the Discourse on Language. Nueva York: Harper \& Row.

-. 2010. The Birth of Biopolitics. Lectures at the College de France, 1978-1979. Nueva York: Picador.

Gammage, Bill. 2011. The Biggest Estate on Earth: How Aborigines Made Australia. Crows Nest, N. S. W.: Allen \& Unwin.

Gandy, Matthew. 2011. "Landscape and Infrastructure in the Late-Modern Metropolis". En New Blackwell Companion to the City, editado por Gary Bridge y Sophie Watson, 57-65. Oxford: Blackwell Publishing.

Garrido, Samuel. 2014. "Water Management, Spanish Irrigation Communities and Colonial Engineers”. Journal of Agrarian Change 14 (3): 400-418. 
Gell, Alfred. 1992. "The Technology of Enchantment and the Enchantment of Technology". En Anthropology, Art and Aesthetics, editado por Jeremy Coote y Anthony Shelton, 40-63. Oxford: Clarendon Press.

—. 1998: Art and Agency. An Anthropological Theory. Oxford; Nueva York: Berg.

Glick, Thomas F. 1996. Irrigation and Hydraulic Technology. Medieval Spain and its Legacy. Aldershot, Hampshire: Variorum.

Godden, Lee y Maureen Tehan, eds. 2010. Comparative Perspectives on Communal Lands and Individual Ownership. Sustainable Futures. Londres; Nueva York: Routledge.

Godelier, Maurice. 1986. “Territory and Property in some Pre-Capitalist Societies”. En The Mental and the Material, editado por Maurice Godelier, 71-121. Londres: Verso.

Gorsky, Martin. 1999. Patterns of Philanthropy. Charity and Society in Nineteenth-Century Bristol. Woodbridge: Boydell.

Granovetter, Mark. 1985. "Economic Action and Social Structure: The Problem of Embeddedness”. American Journal of Sociology 91 (3): 481-510.

Gray, David. 2011. Review of OFWAT and Consumer Representation in the Water Sector. Londres: HMSO.

Greer, Jed y Kenny Bruno. 1996. Greenwash. The Reality behind Corporate Environmentalism. Penang, Malasia: Third World Network.

Halsema, Gerardo van y Linden Vincent. 2006. "Of Flumes, Modules and Barrels. The Failure of Irrigation Institutions and Technologies to Achieve Equitable Water Control in the Indus Basin”. En A History of Water, editado por Terje Tvedt y Eva Jakobsson, 55-91. Londres: I. B. Tauris.

Hann, Chris, ed. 1998. Property Relations: Renewing the Anthropological Tradition. Nueva York: Cambridge University Press.

Haraway, Donna. 2008. When Species Meet. Minnesota, MN: University of Minnesota Press.

Harris, Marvin. 1979. Cultural Materialism: The Struggle for a Science of Culture. Walnut Creek, California: AltaMira Press.

Harris, Leila, Jacqueline Goldin y Christopher Sneddon. 2013. Contemporary Water Governance in the Global South. Scarcity, Marketization and Participation. Londres: Routledge.

Harrison, Peter. 1999. "Subduing the Earth. Genesis 1. Early Modern Science, and the Exploitation of Nature”. The Journal of Religion 79 (1): 86-109.

Harvey, David. 2010. The Enigma of Capital. Oxford; Nueva York: Oxford University Press.

Harvey, Penelope. 2012. "Knowledge and Experimental Practice. A Dialogue between Anthropology and Science and Technology Studies”. En A Handbook of Social Anthropology, editado por Richard Fardon, Olivia Harris, Trevor Marchand, Mark Nuttall, Cris Shore, Veronica Strang y Richard Wilson, 115-129. Londres: Sage Publishers.

Harvey, Penny y Hannah Knox. 2010. "Extraction, Materiality and the 'Science of the Concrete' in Engineering Practice”. En Material Powers. Cultural Studies, History and the Material Turn, editado por Tony Bennett y Patrick Joyce, 124-141. Londres: Routledge. 
-. 2012. "The Enchantments of Infrastructure”. Mobilities 7 (4): 521-536.

Helmreich, Stefan. 2011. “Nature/Culture/Seawater”. American Anthropologist 113 (1): 132-144.

Herzfeld, Michael. 1991. The Social Production of Indifference. Exploring the Symbolic Roots of Western Bureaucracy. Nueva York: Berg.

Hill, Ernestine. (1937) 1965. Water into Gold. The Taming of the Mighty Murray River. Londres; Sídney: Angus \& Robertson.

Himmelfarb, Gertrude. 1995. The De-moralization of Society. From Victorian Virtues to Modern Values. Nueva York: Albert Knopf.

Hirsch, Eric y Marilyn Strathern, eds. 2004. Transactions and Creations. Property Debates and the Stimulus of Melanesia. Nueva York: Berghahn Books.

Hocart, Arthur. (1936) 1970. Kings and Councillors. An Essay in the Comparative Anatomy of Human Society. Chicago; Londres: University of Chicago Press.

Hoekstra, Arjen y Ashok Chapagain. 2007. "Water Footprints of Nations. Water Use by People as a Function of Their Consumption Pattern”. Water Resources Management 21 (1): 35-48.

Homewood, Katherine. 2015. “They Call it Shangri-La'. Sustainable Conservation, or African Enclosures?”. Documento presentado en el Centre for the Anthropology of Sustainability, conferencia inaugural, Anthropological Visions of Sustainable Futures. University College, Londres, 12-14 de febrero.

Huby, Meg y Jonathan Bradshaw. 2012. Water Poverty in England and Wales, Family Resources User Survey. Londres: Royal Statistical Society.

Hughes, Thomas P. 1993. Networks of Power: Electrification in Western Society, 1880-1930. Baltimore, MD: Johns Hopkins University Press.

Jessop, Bob. 2012. "Economic and Ecological Crises: Green New Deals and No-Growth Economies”. Development 55 (1): 17-24.

Kahlown, Muhammad, AD Khan y Muhammad Azam, M. 2006. “The World's Largest Contiguous Irrigation System. Developments, Successes and Challenges in the Indus Irrigation System in Pakistan”. En A History of Water. Vol. 1: Water Control and River Biographies, editado por Terje Tvedt y Eva Jakobsson, 35-54. Londres; Nueva York: I. B. Tauris.

Kirksey, Eben y Stefan Helmreich. 2010. “The Emergence of Multispecies Ethnography”. Cultural Anthropology 25 (4): 545-576.

Knappett, Carl y Lambros Malafouris, eds. 2008: Material Agency. Towards a Non-Anthropocentric Approach. Nueva York: Springer Science.

Kopytoff, Igor. 1986. “The Cultural Biography of Things: Commoditization as Process”. En The Social Life of Things: Commodities in Cultural Perspective, editado por Arjun Appadurai, 64-91. Cambridge: Cambridge University Press.

Krause, Franz y Veronica Strang, eds. 2013. "Living Water. The Powers and Politics of a Vital Substance”. Global Religions, Culture and Ecology 17 (2). DOI: 10.1163 / $15685357-01702001$. 
Ladson, Tony y Brian Finlayson. 2004. "Specifying the Environment's Right to Water. Lessons from Victoria”. Dialogue 23 (3): 19-28.

Lahiri-Dutt, Kuntala, ed. 2006. Fluid Bonds. Views on Gender and Water. Calcuta: Stree.

Lansing, Stephen. 1991. Priests and programmers. Technologies of Power in the Engineered Landscape of Bali. Princeton, N. J.; Oxford: Princeton University Press.

Larkin, Brian. 2013. "The Politics and Poetics of Infrastructure”. Annual Review of Anthropology 42 (1): 327-43.

Latour, Bruno. 2005. Reassembling the Social: An Introduction to Actor-Network-Theory. Oxford: Oxford University Press.

Lawrence, Geoffrey. 2005. "Promoting Sustainable Development. The Question of Governance”. En New Directions in the Sociology of Global Development. Research in Rural Sociology and Development. Vol. 2, editado por Frederick H. Buttel y Philip McMichael, 145-174. Londres: Elsevier.

Lourandos, Harry. 1987. "Swamp Managers of Southwestern Victoria”. En Australians to 1788, editado por Derek John Mulvaney y Peter White, 292-307. Sídney: Fairfax, Syme \& Weldon.

Mains, Daniel. 2012. "Blackouts and Progress. Privatization, Infrastructure, and a Developmentalist State in Jimma, Ethiopia”. Cultural Anthropology 27 (1): 3-27.

Manyika, James, Jonathan Woetzel, Richard Dobbs, Jaana Remes, Eric Labaye y Andrew Jordan. 2015. Global Growth. Can Productivity Save the Day in an Aging World? San Francisco; Shanghai; Londres; París; Nueva York: McKinsey Global Institute. https://www.mckinsey.com/ /media/McKinsey/Featured\%20Insights/Employment\%20and\%20Growth/ Can\%20long\%20term\%20global\%20growth\%20be\%20saved/MGI_Global_growth_Full_ report_February_2015pdf.ashx.

Meissner, Simon. 2012. "Virtual Water and Water Footprints. Global Supply and Production Chains and their Impacts on Freshwater Resources”. En People at the Well. Kinds, Usages and Meanings of Water in a Global Perspective, editado por Hans Peter Hahn, Karlheins Cless y Jens Soentgen, 44-64. Frankfurt; Nueva York: University of Chicago Press.

Milton, Kay, ed. 1993. Environmentalism. The View from Anthropology. ASA Monographs 32. Londres; Nueva York: Routledge.

Minnegal, Monica y Peter Dwyer. 2011. "Appropriating Fish, Appropriating Fishermen: Tradable Permits, Natural Resources and Uncertainty”. En Ownership and Appropriation, editado por Veronica Strang y Mark Busse, 197-215. Oxford; Nueva York: Berg.

Morphy, Howard y Frances Morphy. 2006. “Tasting the Waters: Discriminating Identities in the Waters of Blue Mud Bay”. Journal of Material Culture 11 (1/2): 67-85.

Mosse, David y David Lewis, eds. 2005. The Aid Effect. Giving and Governing in International Development. Londres: Pluto.

Mukerji, Chandra. 2009. Impossible Engineering. Technology and Territoriality on the Canal du Midi. Princeton; Oxford: Princeton University Press.

-. 2010. “The Unintended State”. En Material Powers. Cultural Studies, History and the Material Turn, editado por Tony Bennet y Patrick Joyce, 81-101. Londres: Routledge. 
National Association of Water Companies. 2012. "Public-Private Partnerships". www. nawc.org/our-solutions/public- private-partnerships.aspx.

National Farmers' Federation (NFF). 2015. Submission to the Strengthening Australia's Foreign Investment Framework-Options Paper. Australia: NFF. www.treasury.gov.au/ /media/Treasury/Consultations\%20and\%20Reviews/Consultations/2015/Strengthening\%20 Australias\%20foreign\%20investment\%20framework/Submissions/PDF/National\%20Farmers\%20Federati on.ashx.

Needham, Joseph. 1954-2008. Science and Civilization in China. Taipéi: Caves Books.

Niewöhner, Jörg. 2015. “Anthropology of Infrastructures of Society”. En International Encyclopedia of the Social and Behavioral Sciences. 2. ed., vol. 12, editado por James Wright, 119-125. Oxford: Elsevier.

Norman, Emma, Christina Cook y Alice Cohen, eds. 2015. Negotiating Water Governance. Why the Politics of Scale Matter? Londres: Ashgate.

Office of Water Services (OFWAT) y Environment Agency UK (EA). 2011. The Case for Change: Reforming Water Abstraction Management in England. Birmingham: HMSO.

Orlove, Ben y Steven Caton. 2010. "Water Sustainability. Anthropological Approaches and Prospects”. Annual Review of Anthropology 39: 401-415.

Ortner, Sherry B. 1995. "Resistance and the Problem of Ethnographic Refusal”. Comparative Studies in Society and History 37 (1): 173-193.

Ostrom, Elinor. 1990. Governing the Commons. Cambridge: Cambridge University Press.

-. 2010. "Beyond Markets and States. Polycentric Governance of Complex Economic Systems”. American Economic Review 100 (3): 641-672.

Parliament of the United Kingdom. 2003. The Water Act 2003. UK: Parliament of the United Kingdom.

Pfaffenberger, Bryan. 1990. "The Harsh Facts of Hydraulics. Technology and Society in Sri Lanka’s Colonization Schemes”. Technology and Culture 31: 361-397.

—. 1992. “Technological Dramas”. Science, Technology and Human Values 17 (3): 282-312.

Pietz, David. 2006. "Controlling the Waters in Twentieth-Century China. The Nationalist State and the Huai River". En A History of Water, editado por Terje Tvedt y Eva Jacobsson, 92-119. Londres: I. B. Tauris.

Plumwood, Val. 1993. Feminism and the Mastery of Nature. Londres; Nueva York: Routledge.

-. 2002. Environmental Culture. The Ecological Crisis of Reason. Londres; Nueva York: Routledge.

Polanyi, Karl. 1944. The Great Transformation. Nueva York: Farrar \& Rinehart.

Prochaska, Frank. 2008. "Victorian England. The Age of Societies". En History and Philanthropy. Past, Present and Future, editado por David Cannadine y Jill Pellew, 19-32. Londres: Institute of Historical Research.

Reisner, Marc. 1993. Cadillac Desert. The American West and its Disappearing Water. Harmondsworth: Penguin 
Reynolds, Henry. 1987. The Law of the Land. Londres; Nueva York: Penguin.

Royal Society for Nature Conservation (RSNC). 1992. Dying of Thirst: A Response to the Problem of our Vanishing Wetlands. Newark: The Wildlife Trusts.

Royal Society for the Protection of Birds (RSPB). 2011. "Wetland Loss Threatens Wildlife and People”. www.rspb.org.uk/news/details.aspx?id=283477.

Schaffer, Kay. 1988. Women and the Bush. Forces of Desire in the Australian Cultural Tradition. Cambridge; Melbourne: Cambridge University Press.

Scott, James C. 1998. Seeing Like a State. How Certain Schemes to Improve the Human Condition Have Failed. New Haven; Londres: Yale University Press.

Serpell, James. 1996. In the Company of Animals. A Study of Human-Animal Relationships. Cambridge; Nueva York: Cambridge University Press.

Shiva, Vandana. 2002. Water Wars. Pollution, Profits and Privatization. Londres: Pluto Press.

Smith, Carl Elliot. 2012. Uneven Water Entitlements for Local and Foreign Farm Owners. http:// citizenj.edgeqld.org.au/uneven-water-entitlements-for-local-and-foreign-farm-owners/.

Star, Susan. 1999. “The Ethnography of Infrastructure”. American Behavioral Scientist 43 (3): 377-391.

Stiglitz, Joseph. 2002. Globalization and its Discontents. Nueva York: W. W. Norton.

Strang, Veronica. 1997. Uncommon Ground. Cultural Landscapes and Environmental Values. Oxford; Nueva York: Berg.

-. 2004. The Meaning of Water. Nueva York; Oxford: Berg.

-. 2005. "Knowing Me, Knowing You. Aboriginal and Euro-Australian Concepts of Nature as Self and Other”. Worldviews 9 (1): 25-56.

-. 2006. "A Happy Coincidence? Symbiosis and Synthesis in Anthropological and Indigenous Knowledges”. Current Anthropology 47 (6): 981-1008.

-. 2009. Gardening the World. Agency, Identity, and the Ownership of Water. Oxford; Nueva York: Berghahn Publishers.

-. 2011. "Fluid Forms. Owning Water in Australia". En Ownership and Appropriation, editado por Veronica Strang y Marck Busse, 171-195. Oxford; Nueva York: Berg.

-. 2013. "Dam Nation: Cubbie Station and the Waters of the Darling”. En The Social Life of Water in a Time of Crisis, editado por John R. Wagner, 36-60. Oxford; Nueva York: Berghahn.

-. 2014a. "Lording it over the Goddess. Water, Gender and Human-Environmental Relations”. Journal of Feminist Studies in Religion 30 (1): 83-107.

-. 2014b. "Fluid Consistencies. Meaning and Materiality in Human Engagements with Water”. Archaeological Dialogues 21 (2): 133-150.

-. 2014c. "The Taniwha and the Crown. Defending Water Rights in Aotearoa/New Zealand". WIREs Water 1: 121-131. 
-. 2015. Water, Nature and Culture. Londres: Reaktion Books; University of Chicago Press.

-. 2018. "Re-imagined Communities. A Bioethical Approach to Water Policy". En The Oxford Handbook on Water Politics and Policy, editado por K. Conca y E. Weinthal. Oxford; Nueva York: Oxford University Press.

Strang, Verónica y Marck Busse, eds. 2011. Ownership and Appropriation. Oxford; Nueva York: Berg.

Sultana, Farhana y Alex Loftus, eds. 2012. The Right to Water. Politics, Governance and Social Struggles. Earthscan Water Text Series. Londres; Nueva York: Routledge.

Swyngedouw, Erik. 2015. Liquid Power. Contested Hydro-Modernities in 20th Century Spain. Cambridge: MIT Press.

“Thames Water Paid no UK Corporation Tax for the Year”. 2013. BBC News, 10 de junio. www.bbc.co.uk/news/business-22844952.

Tibby, John, Peter Kershaw, Heather Builth, Aline Philibert y Christopher White. 2006. "Environmental Change and Variability in South-Western Victoria. Changing Constraints and Opportunities for Occupation and Land Use”. En The Social Archaeology of Australian Indigenous Societies, editado por Bruno David, Bryce Barker e Ian McNiven, 254-269. Canberra: Aboriginal Studies Press.

Tilley, Chris. 2007. “Materiality in Materials”. Archaeological Dialogues 14 (1): 16-20.

Tilley, Chris, Webb Keane, Susanne Küchler, Micke Rowlands y Patricia Spyer, eds. 2006. Handbook of Material Culture. Londres; Thousand Oaks; Nueva Deli: Sage.

Tortajada, Cecilia. 2010. "Water Governance. Some Critical Issues”. Water Resources Development 26 (2): 297-307.

Toussaint, Sandy, ed. 2004. Crossing Boundaries. Cultural, Legal, Historical and Practice Issues in Native Title. Carlton: Melbourne University Press.

Tsing, Anna. 2004. Friction. An Ethnography of Global Connections. Princeton: Princeton University Press.

Tvedt, Terje y Eva Jakobsson, eds. 2006. A History of Water. Vol. 1: Water Control and River Biographies. Londres; Nueva York: I. B. Tauris.

Tvedt, Terje y Terje Oestigaard, eds. 2010. A History of Water. Vol. 3: The Idea of Water from Antiquity to Modern Times. Londres: I. B. Tauris.

United Nations Children's Emergency Fund (Unicef). 2015. “Unicef's Latest Data on Water, Sanitation and Hygiene”. www.unicef.org/wash/index_statistics.html.

United Nations General Assembly (UNGA). 2010. The Human Right to Water and Sanitation. Resolution 64/292. París: ONU.

Veolia. 2015. “Discover Veolia”. www.veolia.com/en.

Wagner, John, ed. 2013. The Social Life of Water. Oxford; Nueva York: Berghahn.

Walker, Gareth. 2014. "Water Scarcity in England and Wales as a Failure of (Meta)Governance”. Water Alternatives 7 (2): 388-413. 
Ward, Colin. 1997. Reflected in Water. A Crisis in Social Responsibility. Londres; Washington: Cassell.

Water Technology Net. 2015. “Western Corridor Recycled Water Project, Australia”. www. water-technology.net/projects/western-corridor/.

Wichelns, Dennis. 2015. "Virtual Water and Water Footprints: Overreaching into the Discourse on Sustainability, Efficiency, and Equity”. Water Alternatives 8 (3): 396-414.

Widlok, Thomas y Wolde Gossa Tadesse, eds. 2005. Property and Equality. Vol. 2: Encapsulation, Commercialisation, Discrimination. Nueva York; Oxford: Berghahn Books.

Wittfogel, Karl August. 1957. Oriental Despotism. A Comparative Study of Total Power. New Haven: Yale University Press.

Wolff, Gary y Meena Palaniappan. 2004. "Public or Private Water Management? Cutting the Gordian Knot”. Journal of Water Resources Planning and Management 130 (1): 1-3.

Worster, Donald. 1992. Rivers of Empire: Water, Aridity, and the Growth of the American West. Nueva York: Oxford University Press.

Young, Mike y Jim McColl. 2004. "Parting the Waters. Frontiers in Water Management”. Dialogue 23 (3): 4-18. 